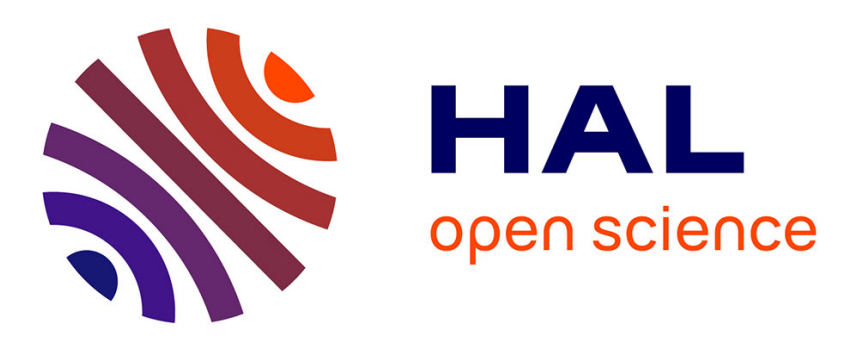

\title{
Numerical modelling of the effect of dry air traces in a helium parallel plate dielectric barrier discharge
}

\author{
C Lazarou, T. Belmonte, a S Chiper, G E Georghiou
}

\section{To cite this version:}

C Lazarou, T. Belmonte, a S Chiper, G E Georghiou. Numerical modelling of the effect of dry air traces in a helium parallel plate dielectric barrier discharge. Plasma Sources Science and Technology, 2016, 25 (5), pp.055023. 10.1088/0963-0252/25/5/055023 . hal-02113593

\section{HAL Id: hal-02113593 \\ https://hal.science/hal-02113593}

Submitted on 10 May 2019

HAL is a multi-disciplinary open access archive for the deposit and dissemination of scientific research documents, whether they are published or not. The documents may come from teaching and research institutions in France or abroad, or from public or private research centers.
L'archive ouverte pluridisciplinaire HAL, est destinée au dépôt et à la diffusion de documents scientifiques de niveau recherche, publiés ou non, émanant des établissements d'enseignement et de recherche français ou étrangers, des laboratoires publics ou privés. 


\title{
Numerical modelling of the effect of dry air traces in a helium parallel plate dielectric barrier discharge
}

\author{
C Lazarou ${ }^{1}$, T Belmonte ${ }^{2,3}$, A S Chiper ${ }^{4}$ and G E Georghiou ${ }^{1}$
}

${ }^{1}$ FOSS Research Centre for Sustainable Energy, Department of Electrical and Computer Engineering, University of Cyprus, Nicosia, 1678, Cyprus

${ }^{2}$ Institut Jean Lamour, Université de Lorraine, UMR CNRS 7198, NANCY, F-54042, France

${ }^{3}$ CNRS, Institut Jean Lamour, UMR CNRS 7198, NANCY, F-54042, France

${ }^{4}$ Iasi Plasma Advanced Research Center (IPARC), Faculty of Physics, Alexandru Ioan Cuza

University of Iasi, Iasi, Romania 700506

E-mail: lazarou.constantinos@ucy.ac.cy

\begin{abstract}
A validated numerical model developed for the study of helium barrier discharges in the presence of dry air impurities is presented in this paper. The model was used to numerically investigate the influence of air traces on the evolution of the helium dielectric barrier discharge (DBD). The level of dry air used as impurity was in the range from 0 to $1500 \mathrm{ppm}$, which corresponds to the most commonly encountered range in atmospheric pressure discharge experiments. The results presented in this study clearly show that the plasma chemistry and consequently the discharge evolution is highly affected by the concentration level of impurities in the mixture. In particular, it was observed that air traces assist the discharge ignition at low concentration levels $(\sim 55 \mathrm{ppm})$, while on the other hand, they increase the burning voltage at higher concentration levels $(\sim 1000 \mathrm{ppm})$. Furthermore, it was found that the discharge symmetry during the voltage cycle highly depends on the concentration of air. For the interpretation of the results, a detailed analysis of the processes that occur in the discharge gap is performed and the main reaction pathways of ion production are described. Thanks to this approach, useful insight into the physics behind the evolution of the discharge is obtained.
\end{abstract}

\section{Introduction}

Low temperature plasma processes at atmospheric pressure have gained tremendous attention in recent years due to their low production cost and the wide range of applications they are suitable for, ranging from surface modification [1-3], plasma medicine [4-6], sterilization [7-9] etc. An easy and effective solution to achieve low temperature plasma is by covering one or both electrodes with a dielectric layer, which inhibits the transition to arcing, thus keeping the plasma at room temperature [10]. By using such an arrangement, which is called dielectric barrier discharge (DBD), two different modes of discharge, namely, the filamentary and homogeneous mode can be achieved [11]. In particular, the filamentary mode comprises of a large number of individual micro-discharges, while in the homogeneous mode, the plasma covers uniformly the whole electrode area.

The homogeneous mode, also known as diffuse mode, appears to exhibit the discharge characteristic of the glow or Townsend discharge depending on the working gas. Gases such as helium or neon exhibit the characteristics of the glow mode [12-18], while for the case of nitrogen gas, the characteristics of the Townsend discharge mode are observed [19-22]. However, recently the Townsend mode has also been observed in helium barrier discharges $[23,24]$. It is worth noting that selected operational parameters (e.g. frequency, amplitude of the applied voltage, dielectric type and dimensions, carrier gas and its purity, etc.) are required to generate a homogeneous discharge $[25,26]$. In industry the homogeneous mode is preferred because it provides uniform treatment and is free from micro-discharges that can damage sensitive surfaces.

The presence of air traces is unavoidable in all atmospheric pressure gas discharges and has to be taken into account. Moreover, it is observed from experiments and simulations that 
even a small amount of impurities significantly affects the plasma characteristics [24,27-34]. With this in mind, a one dimensional plasma fluid model was developed for the physical description of the helium dielectric barrier discharge (DBD) in the presence of dry air as impurity. The model takes into account the analytical chemistry of helium with nitrogen and oxygen species and it was verified with experimental results in order to ensure its validity. Then the level of air was varied in the range of $0-1500 \mathrm{ppm}$ and its effect on the discharge evolution was investigated.

In the literature, there are several studies investigating numerically the effect of impurities in helium discharges, $\mathrm{He}+\mathrm{N}_{2}[27,30-32,35-38], \mathrm{He}+\mathrm{O}_{2}[28,39,40]$ and $\mathrm{He}+$ air $[41-$ 45]. However, there is no reference regarding the effect of dry air impurities on the discharge evolution in a wide range of compositions. In this study, it was observed that the concentration level of air significantly affects the plasma chemistry and consequently the discharge evolution. Hence, it is very important to understand the effect of the air traces on discharge evolution, in order to be able to characterize applications that are based on helium DBDs. The paper is arranged as follows: after a short description of the model used to describe the behaviour of discharges and the input parameters required to feed the model, results that validate the model with experimental observations are presented. Next, the influence of the concentration level of air is described to shed light on the characterisitcs of such discharges.

\section{Model}

A one-dimensional plasma fluid model [46] was developed and validated and was subsequently used to study the effect of the concentration of dry air $\left(79 \% \mathrm{~N}_{2}\right.$ and $\left.21 \% \mathrm{O}_{2}\right)$ in a helium dielectric barrier discharge. A two-dimensional treatment was deemed computationally very expensive and as a result the one-dimensional model was employed in this work. This is possible for a qualitative analysis, when the discharge has the characteristics of the homogeneous DBD. The numerical model was validated with the experimental results of [15]. The experimental setup that was used for the validation mainly consists of two parallel electrodes covered by dielectric layers of the same thickness. On one of the electrodes a high voltage is applied, while the other is grounded. The gap between the dielectric layers is filled with helium gas (purity of $99.999 \mathrm{vol} \%$ ) at atmospheric pressure, after the discharge cell was pumped down to $10 \mathrm{~Pa}$. The experimental setup and operational parameters, reported in [15], are summarized in Table 1. It is noted that the discharge exhibits the characteristics of the homogenous mode.

\subsection{Model equations:}

In this study, electrons are described by the first three moments of the Boltzmann equation, which after simplification converge to the continuity equation in the drift-diffusion approximation $[47,48]$. For the description of the remaining species in the mixture (heavy species), the multi-component diffusion equation was used [49,50]. The equations for electrons and heavy species are coupled with Poisson's equation for the description of the electric field. The details of the equations have already been thoroughly described in [27], and as a result the model is only briefly presented here.

The electron and electron energy densities are obtained by the following equations:

$$
\begin{gathered}
\frac{\partial n_{e}}{\partial t}+\nabla \cdot \vec{\Gamma}_{e}=S_{e} \\
\frac{\partial n_{\varepsilon}}{\partial t}+\nabla \cdot \vec{\Gamma}_{\varepsilon}=-e \vec{\Gamma}_{e} \cdot \vec{E}+S_{\varepsilon}
\end{gathered}
$$

where $n_{e}$ and $n_{\varepsilon}$ represent the densities of electron and electron energy respectively, $\vec{\Gamma}_{e}$ and $\vec{\Gamma}_{\varepsilon}$ are the flux terms for the electron and electron energy respectively, $\vec{E}$ is the electric field, $S_{e}$ is the source term which describes the net rate change of electron density due to chemical 
reactions, $S_{\varepsilon}$ is the electron energy source term which accounts for the loss or gain of energy from inelastic collisions of electrons with heavy species. The heavy species in the mixture (with the exception of the background gas) are described by the multi-component equation:

$$
\rho \frac{\partial}{\partial t}\left(w_{k}\right)=\nabla \cdot \vec{\jmath}_{k}+S_{k} \quad k=1, \ldots, Q-1
$$

where $\rho$ is the density of the mixture, $w_{k}$ is the mass fraction of species $k, \vec{J}_{k}$ is the diffusive flux vector, $S_{k}$ is the source term and $Q$ is the number of heavy species in the mixture. The density of the background gas is given by the equation:

$$
w=1-\sum_{k=1}^{Q-1} w_{k}
$$

Finally, Poisson's equation provides the space charge electric field:

$$
\nabla \cdot\left(\varepsilon_{r} \nabla \varphi\right)=\rho_{v}
$$

where $\varepsilon_{r}$ is the dielectric constant of the material, $\varphi$ is the potential and $\rho_{v}$ is the local charge in the gap.

\begin{tabular}{|l|c|}
\hline \multicolumn{2}{|l|}{ Table 1: Operational parameters of experimental setup from [15]. } \\
\hline Relative permittivity $\left(\varepsilon_{\mathrm{r}}\right)$ & 9.4 \\
\hline Gap between dielectrics $(\mathrm{mm})$ & 5 \\
\hline Dielectric thickness $(\mathrm{mm})$ & 0.7 \\
\hline Electrode area $\left(\mathrm{cm}^{2}\right)$ & 4 \\
\hline Gas pressure $(\mathrm{atm})$ & 1 \\
\hline Gas temperature $(\mathrm{K})$ & 300 \\
\hline Voltage $_{\mathrm{p}-\mathrm{p}}(\mathrm{kV})$ & 2 \\
\hline Voltage waveform & sinusoidal \\
\hline Frequency $(\mathrm{kHz})$ & 10 \\
\hline Helium gas purity $(\%)$ & 99.999 \\
\hline
\end{tabular}

\subsection{Boundary conditions}

The boundary conditions considered for the flux of electrons and electron energy from the solid surface are given by the following equations:

$$
\begin{gathered}
-\vec{n} \cdot \vec{\Gamma}_{e}=\left(\frac{1}{2} v_{e, t h} n_{e}+n_{e} \mu_{e} \vec{E} \cdot \vec{n}\right)-\sum_{p=1}^{Q} \gamma_{p} \overrightarrow{\Gamma_{p}} \cdot \vec{n} \\
-\vec{n} \cdot \vec{\Gamma}_{\varepsilon}=\left(\frac{5}{6} v_{e, t h} n_{\varepsilon}+n_{\varepsilon} \mu_{\varepsilon} \vec{E} \cdot \vec{n}\right)-\sum_{p=1}^{Q} \gamma_{p} \varepsilon_{p} \overrightarrow{\Gamma_{p}} \cdot \vec{n}
\end{gathered}
$$

where $\vec{n}$ is the outward normal to the solid surface, $v_{e, t h}$ is the thermal velocity, $\mu_{e}$ and $\mu_{\varepsilon}$ are the electron and electron energy mobility respectively, $\gamma_{p}$ is the secondary electron emission coefficient (seec) of species $p, \overrightarrow{\Gamma_{p}}$ is the flux of the species $p$ and $\varepsilon_{p}$ is the mean initial energy 
of secondary electrons (mese) emitted from the solid surface. The two terms in the parenthesis, on the right hand side of equation 5 represent the loss of electrons on the solid surface, due to the random motion of electrons and the flux of electrons due to the electric field. On the other hand, the last term on the right hand side of equation 5 represents the gain of electrons due to secondary electron emission. Similar explanation applies to equation 6 concerning the electron energy.

The normal component of the heavy species flux from the solid surface is given by

$$
-\vec{n} \cdot \vec{\jmath}_{k}=M_{k} R_{\text {surf }, k}+M_{k} c_{k} \mu_{k, m} z_{k}(\vec{n} \cdot \vec{E})\left(z_{k} \vec{n} \cdot \vec{E}\right)>0
$$

where $M_{k}$ is the molar weight of species $k, R_{s u r f, k}$ is the surface reaction rate, $c_{k}$ represents the mass fraction of species $k, \mu_{k, m}$ is the mixture-averaged mobility and $z_{k}$ is the charge number of species $k$. The first term on the right hand side of equation $7\left(R_{s u r f, k}\right)$ is linked to the way species are created or lost on the solid surfaces, while the second term represents the loss of ions due to the movement driven by the electric field. For the neutral species, the second term on the right hand side of equation 7 is zero. The surface reaction rate is given by

$$
R_{\text {surf }, k}=c_{k} \sum_{i=1}^{N} v_{i, k} \frac{\gamma_{i}}{\left(1-\gamma_{i} / 2\right)} \frac{1}{4} \sqrt{\frac{8 R T_{g}}{\pi M_{n}}}
$$

where $N$ is the number of surface reactions, $v_{i, k}$ is the stoichiometric number of species $k$ on the $i^{\text {th }}$ surface reaction, $\gamma_{i}$ is the probability of the reaction to occur (sticking coefficient), $R$ is the universal constant, $T_{g}$ is the gas temperature and $M_{n}$ is the mean mass of the mixture. The reaction rate (equation 8) is attributed to the random motion of species with Maxwellian velocity distribution function times the probability of a collision happening (sticking coefficient). The term $1 /\left(1-\gamma_{i} / 2\right)$ represents the Motz-Wise correction, which is a corrector term for reactions with high probability, when the velocity distribution of the species is nonMaxwellian. The field generated by the charge accumulated on the dielectrics is calculated from the following equation

$$
\hat{n} \cdot\left(\vec{D}_{1}-\vec{D}_{2}\right)=\rho_{s}
$$

where $\vec{D}_{1}$ and $\vec{D}_{2}$ are the electric displacement field above and below the boundary and $\rho_{s}$ is the surface charge density which can be obtained from the following ordinary differential equation on the boundary

$$
\frac{\partial \rho_{s}}{\partial t}=\vec{n} \cdot \vec{J}_{e}+\vec{n} \cdot \vec{J}_{i}
$$

where $\vec{J}_{i}$ and $\vec{J}_{e}$ are the ion and electron current densities on the wall respectively. All the equations presented in section 2.1 and 2.2 are solved by using the Plasma module of the COMSOL multiphysics simulation package [51].

\section{Input parameters}

For the description of the experiment presented in section 2, 27 species and 151 reaction channels were considered. The species included in the model are electrons, $\mathrm{He}^{+}$and $\mathrm{He}_{2}{ }^{+}$ions, $\mathrm{He}$ ground-state atoms, $\mathrm{He}_{2}{ }^{*}$ excimers, $\mathrm{He}_{\mathrm{m}}$ excitation to metastable atoms $\mathrm{He}\left(2^{3} \mathrm{~S}\right)$ and $\mathrm{He}\left(2^{1} \mathrm{~S}\right), \mathrm{N}_{2}{ }^{+}$and $\mathrm{N}_{4}{ }^{+}$ions, $\mathrm{N}_{2}$ ground state molecules and $\mathrm{N}$ atoms, $\mathrm{N}_{2}(\mathrm{~A}), \mathrm{N}_{2}(\mathrm{~B}), \mathrm{N}_{2}(\mathrm{a})$ and $\mathrm{N}_{2}(\mathrm{C})$ nitrogen excited species, $\mathrm{O}, \mathrm{O}_{2}$ and $\mathrm{O}_{3}$ ground state atoms, molecules and polyatomic molecules, $\mathrm{O}_{2}(\mathrm{v})$ vibrational excited states $(\mathrm{v}=1-4), \mathrm{O}^{-}, \mathrm{O}_{2}^{-}, \mathrm{O}_{3}{ }^{-}, \mathrm{O}_{2}{ }^{+}$and $\mathrm{O}_{4}{ }^{+}$ions, $\mathrm{O}^{1} \mathrm{~S}$ and $\mathrm{O}^{1} \mathrm{D}$ excited atoms, $\mathrm{O}_{2}\left(\mathrm{a}_{1} \Delta_{\mathrm{g}}\right)$ and $\mathrm{O}_{2}\left(\mathrm{~b}^{1} \Sigma_{\mathrm{g}}{ }^{+}\right)$excited molecules. Based on the idea of [52], the species $\mathrm{N}_{2}(\mathrm{~A})$ represents the excitation of $\mathrm{N}_{2}$ at $\mathrm{N}_{2}\left(\mathrm{~A}^{3} \Sigma_{\mathrm{u}}^{+}(\mathrm{v}=0-4)\right), \mathrm{N}_{2}\left(\mathrm{~A}^{3} \Sigma_{\mathrm{u}}^{+}(\mathrm{v}=5-\right.$ $9)$ ) and $\mathrm{N}_{2}\left(\mathrm{~A}^{3} \Sigma_{\mathrm{u}}^{+}(\mathrm{v}>9)\right)$, the species $\mathrm{N}_{2}(\mathrm{~B})$ represents the excitation of $\mathrm{N}_{2}$ at 
$\mathrm{N}_{2}\left(\mathrm{~B}^{3} \Pi_{\mathrm{g}}\right), \mathrm{N}_{2}\left(\mathrm{~W}^{3} \Delta_{\mathrm{u}}\right)$ and $\mathrm{N}_{2}\left(\mathrm{~B}^{3} \Sigma_{\mathrm{u}}^{-}\right)$, the species $\mathrm{N}_{2}\left(\right.$ a) represents the excitation of $\mathrm{N}_{2}$ at $\mathrm{N}_{2}\left(\mathrm{a}^{1} \Sigma_{\mathrm{u}}^{-}\right), \mathrm{N}_{2}\left(\mathrm{a}^{1} \Pi_{\mathrm{g}}\right)$ and $\mathrm{N}_{2}\left(\mathrm{~W}^{1} \Delta_{\mathrm{u}}\right)$ and the species $\mathrm{N}_{2}(\mathrm{C})$ represents the excitation of $\mathrm{N}_{2}$ at $\mathrm{N}_{2}\left(\mathrm{C}^{3} \Pi_{\mathrm{u}}\right), \mathrm{N}_{2}\left(\mathrm{E}^{3} \Sigma_{\mathrm{g}}^{+}\right)$and $\mathrm{N}_{2}\left(\mathrm{a}^{1} \Sigma_{\mathrm{g}}^{+}\right)$. The NOx molecules were not considered in the kinetic scheme because they increase the computational time without affecting significantly the simulation results. The kinetic scheme (reaction channels) used is mainly taken from $[28,38,45,52-55]$.

The electron transport parameters and the rate coefficients of reactions 1-4, 28-41 and 63-74 (see Table 5 in Appendix A), which are used as input parameters in the fluid model, are calculated by averaging specific quantities and the electron impact cross sections over the electron energy distribution function (EEDF) $[48,56]$. This indicates the importance of the chosen EEDF and electron impact cross sections on the simulation results. In the literature, the EEDF can be calculated from predefined functions (Maxwellian, Druyvesteyn and Generalized) or from the solution of Boltzmann's equation. On the other hand, the electron impact cross sections are available on the open access LXCat website [57].

For a low-temperature non-equilibrium plasma, calculating the EEDF by solving Boltzmann's equation constitutes the only consistent way to build the fluid model [48]. There are two approaches to solve Boltzmann's equation: either kinetic [48] or statistical [58,59]. However, for the case of helium, both methods give similar results [60]. This is not true for other gases. In this paper, the two term-approximation (kinetic) as described by [48] is used to solve Boltzmann's equation.

Moreover, input parameters such as: electron concentration, gas temperature, ionization degree, mole fractions of some species and the electron impact cross sections are required to solve Boltzmann's equation. The gas temperature is set the same as the temperature of the experiment, while the electron density is estimated from the experimental discharge current. Since the discharge in the experiment exhibits the characteristics of the homogeneous mode, the gas is assumed to be weakly ionized [11,61]. The mole fraction of species $\mathrm{He}_{\mathrm{m}}, \mathrm{O}, \mathrm{O}_{2}(\mathrm{v}), \mathrm{O}_{2}(\mathrm{a})$ and $\mathrm{O}_{2}(\mathrm{~b})$ is estimated from [28], based on the level of oxygen impurities that is used in the simulation model. For this study, the concentration of air was set at $80 \mathrm{ppm}$ because this value gave the best agreement with the experimental results.

From the above analysis, the input parameters for the Boltzmann solver are defined as follows: gas temperature $\mathrm{T}_{\mathrm{g}}=300 \mathrm{~K}$, electron density $=10^{20} \mathrm{~m}^{-3}$, ionization degree $=10^{-7}$, mole fraction of $\mathrm{He}_{\mathrm{m}}=2 \cdot 10^{-9}, \mathrm{O}=10^{-7}, \mathrm{O}_{2}(b)=10^{-8}, \mathrm{O}_{2}(a)=5 \cdot 10^{-8}, \mathrm{O}_{2}(v)=6$. $10^{-9}$ and mole fraction of air $=0.8 \times 10^{-4}\left(79 \% \mathrm{~N}_{2}\right.$ and $\left.21 \% \mathrm{O}_{2}\right)$. The chosen electron impact cross section will be analysed in the following paragraph. It is also worth noting that the electron impact cross sections affect both the calculation of the EEDF and the rate coefficients. The EEDF calculated at $80 \mathrm{ppm}$ level of air was used for all air concentrations, since it does not change significantly in the range of air concentrations considered in this study (see Figure 1).

Concerning the electron impact cross sections, these should be complete and consistent [60,62-64]. The term 'complete' means that the chosen database should be able to describe the main electron momentum-loss, energy-loss and number-changing processes (ionization, attachment, and recombination). On the other hand, 'consistent' refers to the ability of the database to predict correctly the electron swarm parameters when this database is used as input to the Boltzmann solver [48]. More details about the different databases for electron impact cross section and the chosen criteria are described in the literature [60,62-64]. In this paper, the Morgan database is used for the description of the electron scattering cross section with the $\mathrm{He}$ gas, while for the $\mathrm{N}_{2}$ and $\mathrm{O}_{2}$ gases, the IST-Lisbon database was used $[65,66]$. These databases are complete and predict the swarm parameters with good accuracy $[60,67]$. For the electron impact excitation of $\mathrm{O}$ atoms to $\mathrm{O}\left({ }^{1} S\right)$ and the attachment of $\mathrm{O}_{2}\left(\mathrm{a}_{1} \Delta_{\mathrm{g}}\right), \mathrm{O}_{2}\left(\mathrm{~b}^{1} \Sigma_{\mathrm{g}}{ }^{+}\right)[65]$ and $\mathrm{O}_{2}(\mathrm{v})$ [68], the Morgan and TRINITI databases are used. All the parameters used for the calculation of the EEDF are summarized in Table 2.

The diffusion coefficients for the species $\mathrm{He}, \mathrm{He}_{\mathrm{m}}, \mathrm{He}^{+}, \mathrm{He}_{2}{ }^{+}, \mathrm{N}, \mathrm{N}_{2}, \mathrm{~N}_{2}(\mathrm{~A}), \mathrm{N}_{2}$ (B), $\mathrm{N}_{2}(\mathrm{a}), \mathrm{N}_{2}(\mathrm{C}), \mathrm{N}_{2}{ }^{+}, \mathrm{N}_{4}{ }^{+}, \mathrm{O}, \mathrm{O}_{2}, \mathrm{O}_{3}, \mathrm{O}^{-}, \mathrm{O}_{2}^{-}, \mathrm{O}_{3}^{-}, \mathrm{O}_{2}{ }^{+}, \mathrm{O}_{4}{ }^{+}, \mathrm{O}^{1} \mathrm{~S}, \mathrm{O}^{1} \mathrm{D}, \mathrm{O}_{2}\left(\mathrm{a}_{1} \Delta_{\mathrm{g}}\right)$ and $\mathrm{O}_{2}\left(\mathrm{~b}^{1} \Sigma_{\mathrm{g}}{ }^{+}\right)$are calculated from the kinetic theory $[69,70]$. For the excited species, the diffusion coefficient is considered the same as for their corresponding neutral species. The diffusion coefficient of 
$\mathrm{He}_{2} *$ is taken from [71] and the mobilities of $\mathrm{He}_{2}{ }^{+}, \mathrm{N}_{4}{ }^{+}, \mathrm{O}_{4}{ }^{+}$are taken from experimental values [72,73].

The surface reactions, reaction probabilities, seec and mese considered on the dielectric surface are given in Table 3. The surface reactions and reaction probabilities are taken from $[28,74,75]$. On the other hand, the electrons emitted from the dielectric surface are attributed to the intrinsic electrons and the trapped electrons in the shallow traps of dielectric surfaces. The latter mechanism has the most important contribution, since these electrons require less energy to be released [11]. However, the secondary electron emission coefficient is not trivial because the surface charges on the dielectrics are not known and in most cases this is considered as an "adjustable parameter" [76,77]. For that reason, the seec is varied until simulation and experimental results match. It is important to note that the energy required to release electrons from the dielectric surfaces is taken mainly from the ions and excited species that remain in the discharge gap from the previous breakdown [11].

For the case of atmospheric pressure glow discharge (APGD), this energy is mainly provided by the "memory" ions that remain in the positive column region [12] from the previous breakdown. On the other hand, for atmospheric pressure Townsend discharge (APTD), this energy is provided by the "memory" excited species, which are created close to the anode from the previous breakdown. More details on this point can be found in [11]. As in the experiment [15], the discharge has the characteristics of the APGD and it was assumed that only "memory" ions are responsible for extracting electrons from the dielectrics. In our simulation, the seec which gave the best results in reproducing the experimental results are summarized in Table 3.

The mean initial energy of the released electrons depends on the ion energy (ionization energy). It is noted that the helium ions have higher energy compared to the nitrogen and oxygen ions (see Appendix A, Table 5). For the helium ions, a mean initial energy of $5 \mathrm{eV}$ for the secondary electrons was used which was the same as in [46], while for nitrogen and oxygen a mean initial energy of $3 \mathrm{eV}$ was used since these ions have lower intrinsic energy.

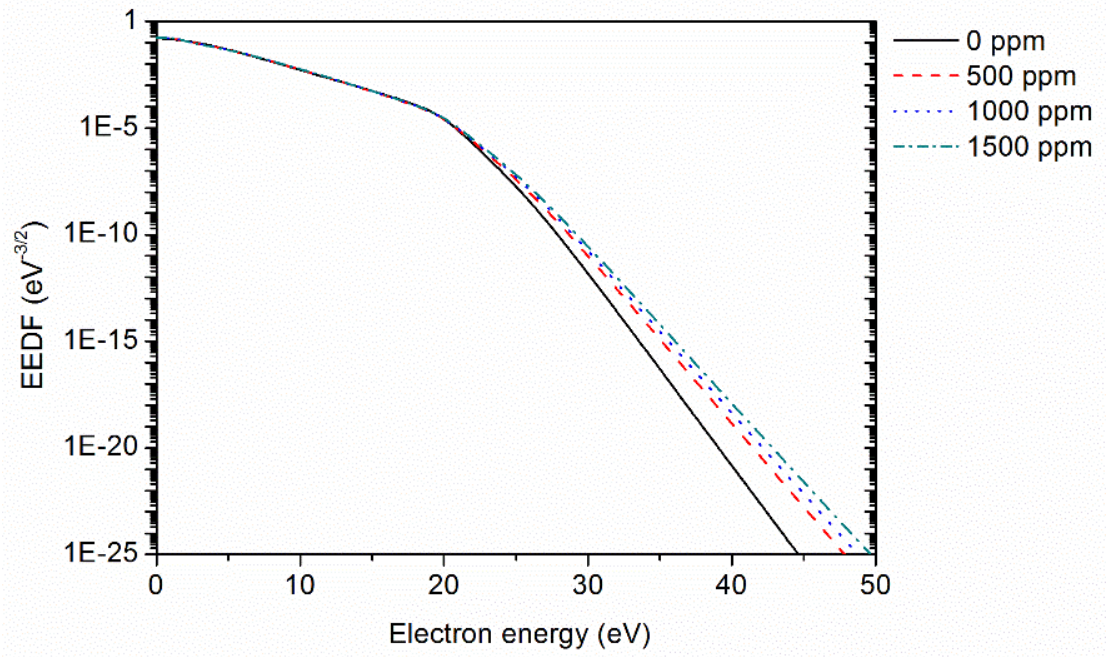

Figure 1: Comparison of the different EEDFs as a function of electron energy, at a mean electron energy of $4 \mathrm{eV}$.

\begin{tabular}{|l|l|}
\hline \multicolumn{2}{|l|}{ Table 2: Input parameters for the Boltzmann solver [48,51]. } \\
\hline Gas temperature & $300 \mathrm{~K}$ \\
\hline Electron density & $10^{20} \mathrm{~m}^{-3}$ \\
\hline Ionization degree & $10^{-7}$ \\
\hline $\mathrm{He}_{\mathrm{m}}$ mole fraction & $2 \cdot 10^{-9}$ \\
\hline $\mathrm{O}$ mole fraction & $1 \cdot 10^{-7}$ \\
\hline $\mathrm{O}_{2}(\mathrm{~b})$ mole fraction & $1 \cdot 10^{-8}$ \\
\hline $\mathrm{O}_{2}(\mathrm{a})$ mole fraction & $5 \cdot 10^{-8}$ \\
\hline $\mathrm{O}_{2}(\mathrm{v})$ mole fraction & $6 \cdot 10^{-9}$ \\
\hline
\end{tabular}




\begin{tabular}{|l|l|}
\hline $\mathrm{N}_{2}$ mole fraction & $6.32 \times 10^{-5}(79 \%$ of $80 \mathrm{ppm}$ of Air $)$ \\
\hline $\mathrm{O}_{2}$ mole fraction & $1.68 \times 10^{-5}(21 \%$ of $80 \mathrm{ppm}$ of Air $)$ \\
\hline
\end{tabular}

\begin{tabular}{|c|c|c|c|c|}
\hline No & Surface Reaction ${ }^{\text {a) }}$ & Reaction probability ${ }^{\text {a) }}$ & seec & mese \\
\hline 1 & $\mathrm{He}_{\mathrm{m}}^{*}+$ Surface $\rightarrow \mathrm{He}$ & 1 & 0 & 0 \\
\hline 2 & $\mathrm{He}_{2}^{*}+$ Surface $\rightarrow 2 \mathrm{He}$ & 1 & 0 & 0 \\
\hline 3 & $\mathrm{He}^{+}+$Surface $\rightarrow \mathrm{He}$ & 1 & $2 \cdot 10^{-2}$ & 5 \\
\hline 4 & $\mathrm{He}_{2}^{+}+$Surface $\rightarrow 2 \mathrm{He}$ & 1 & $2 \cdot 10^{-2}$ & 5 \\
\hline 5 & $\mathrm{~N}+$ Surface $\rightarrow 0.5 \mathrm{~N}_{2}$ & 0.01 & 0 & 0 \\
\hline 6 & $\mathrm{~N}_{2}(A)+$ Surface $\rightarrow \mathrm{N}_{2}$ & 0.5 & 0 & 0 \\
\hline 7 & $\mathrm{~N}_{2}(B)+$ Surface $\rightarrow \mathrm{N}_{2}$ & 0.5 & 0 & 0 \\
\hline 8 & $\mathrm{~N}_{2}(a)+$ Surface $\rightarrow \mathrm{N}_{2}$ & 0.5 & 0 & 0 \\
\hline 9 & $\mathrm{~N}_{2}(C)+$ Surface $\rightarrow \mathrm{N}_{2}$ & 0.5 & 0 & 0 \\
\hline 10 & $\mathrm{~N}_{2}^{+}+$Surface $\rightarrow \mathrm{N}_{2}$ & 1 & $1 \cdot 10^{-3}$ & 3 \\
\hline 11 & $\mathrm{~N}_{4}^{+}+$Surface $\rightarrow 2 \mathrm{~N}_{2}$ & 1 & $1 \cdot 10^{-3}$ & 3 \\
\hline 12 & $0+$ Surface $\rightarrow 0.5 \mathrm{O}_{2}$ & 0.02 & 0 & 0 \\
\hline 13 & $\mathrm{O}\left({ }^{1} D\right)+$ Surface $\rightarrow 0$ & 1 & 0 & 0 \\
\hline 14 & $\mathrm{O}\left({ }^{1} S\right)+$ Surface $\rightarrow 0$ & 1 & 0 & 0 \\
\hline 15 & $\mathrm{O}_{2}(v)+$ Surface $\rightarrow \mathrm{O}_{2}$ & 0.2 & 0 & 0 \\
\hline 16 & $\mathrm{O}_{2}(a)+$ Surface $\rightarrow \mathrm{O}_{2}$ & 0.0004 & 0 & 0 \\
\hline 17 & $\mathrm{O}_{2}(b)+$ Surface $\rightarrow \mathrm{O}_{2}$ & 0.02 & 0 & 0 \\
\hline 18 & $\mathrm{O}_{3}+$ Surface $\rightarrow \mathrm{O}_{3}$ & 1 & 0 & 0 \\
\hline 19 & $\mathrm{O}^{-}+$Surface $\rightarrow 0.5 \mathrm{O}_{2}$ & 1 & 0 & 0 \\
\hline 20 & $\mathrm{O}_{2}^{-}+$Surface $\rightarrow \mathrm{O}_{2}$ & 1 & 0 & 0 \\
\hline 21 & $\mathrm{O}_{3}^{-}+$Surface $\rightarrow \mathrm{O}_{3}$ & 1 & 0 & 0 \\
\hline 22 & $\mathrm{O}_{2}^{+}+$Surface $\rightarrow \mathrm{O}_{2}$ & 1 & $2 \cdot 10^{-5}$ & 3 \\
\hline 23 & $\mathrm{O}_{4}^{+}+$Surface $\rightarrow 2 \mathrm{O}_{2}$ & 1 & $2 \cdot 10^{-5}$ & 3 \\
\hline \multicolumn{5}{|c|}{${ }^{\mathrm{a}}$ ref $[28,74,75]$} \\
\hline
\end{tabular}

\section{Results and discussion}

An important part of this study is the development of an appropriate model for the description of helium discharges in the presence of dry air impurities. In order to ensure its correctness, the model was validated with experimental results [15]. Then, the level of air impurities was varied and its effect on plasma dynamics and chemistry was studied. Given that the breakdown has the characteristics of the homogeneous mode, the use of a one dimensional model to interpret the experimental results is justified.

\subsection{Model validation:}

The validation of the model is based on the electrical measurements from the experiment described in [15]. The quantities, which were compared with the simulation results, are: the discharge current, the breakdown voltage, the memory voltage and the amplitude of the applied voltage when breakdown occurs. Figure 2 shows the comparison between the experimental results reported in [15], for atmospheric pressure DBD working in He (purity 99.999 vol\%) after $99.99 \%$ of the air from the discharge chamber was previously removed, and our simulation results for DBD in He with $80 \mathrm{ppm}$ air impurities. Here the air concentration was set at $80 \mathrm{ppm}$ because this gave the best reproduction of the experimental results. From Figure 2, a very good agreement is observed. In particular, the simulation discharge current and breakdown voltage have an error of less than 2.5 and $10 \%$ respectively compared to the experimental results. These 
errors are within acceptable limits. Furthermore, breakdown occurred at about $0.7 \mathrm{kV}$, both for the simulation and experiment. The simulation results presented correspond to the $9^{\text {th }}$ voltage cycle after steady-state has been reached. Specifically, steady-state is typically reached 2-3 ac cycles after the first breakdown.

The above validation of the simulation results provides us confidence about the ability of the model to capture the physics behind this kind of discharges and as a result it was subsequently used to study the effect of dry air traces on the discharge evolution.
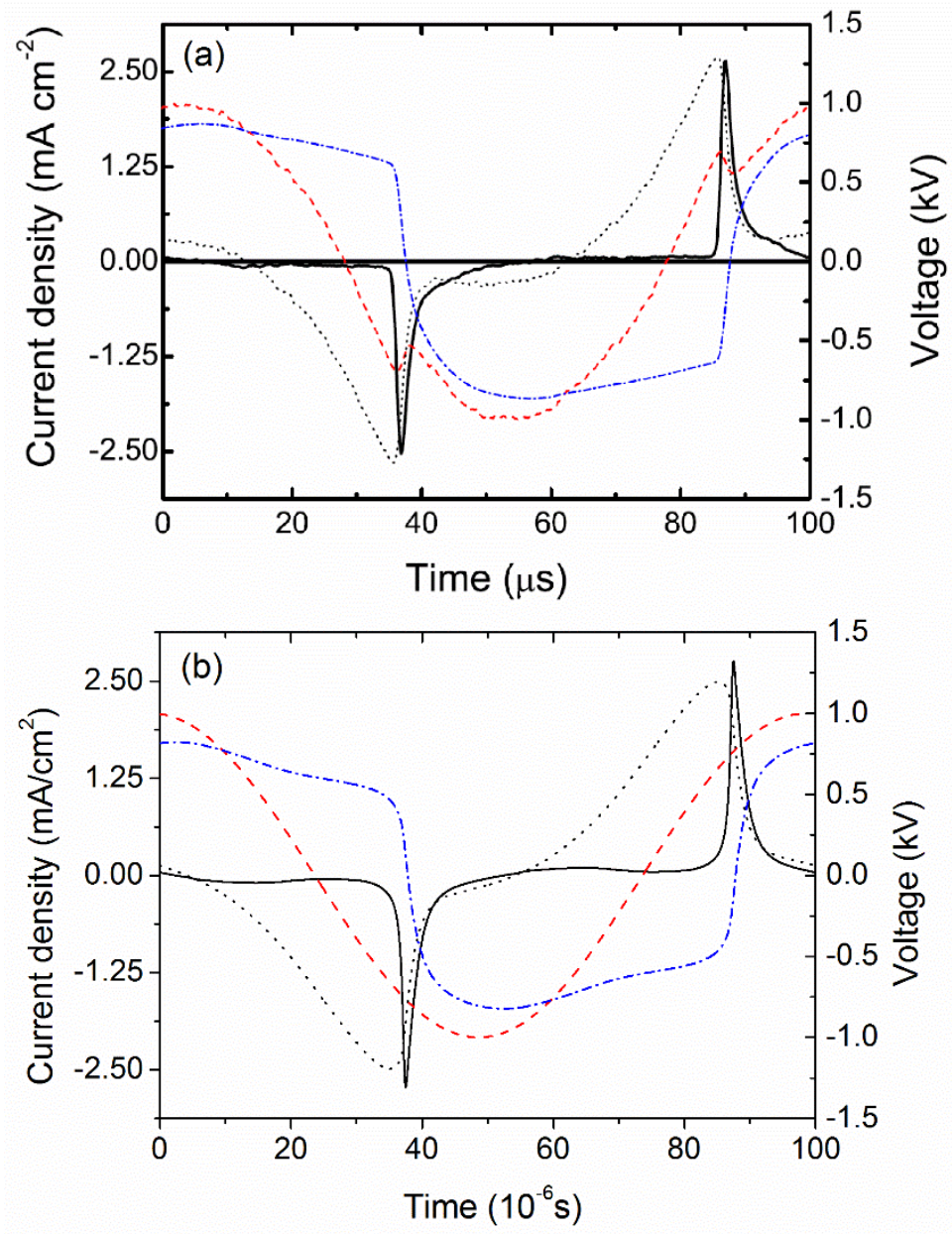

Figure 2: Comparison between (a) the experimental results reported in [15] for atmospheric pressure DBD working in He (purity 99.999 vol\%) and (b) our simulation results for DBD in He with $80 \mathrm{ppm}$ air impurities. The black line represents the discharge current, the dashed red line the applied voltage, the dotted black line the gap voltage and the dashed dotted blue line the memory voltage.

\subsection{Effect of dry air concentration in helium DBD:}

The dry air contents in the Helium DBD were investigated in the range from 0 to $1500 \mathrm{ppm}$. For a better interpretation of the results, this range was divided into four sub-ranges based on the following criteria: the discharge ignition, the discharge mode and the symmetry of the discharge current. With the term symmetric current we mean that the current exhibits the same behaviour during both parts of the voltage cycle, but with a different sign. The four different cases are presented in Table 4. 


\begin{tabular}{|c|c|c|c|c|}
\hline \multicolumn{6}{|c|}{ Table 4: Different cases considered in the simulations. } \\
\hline Case & $\begin{array}{c}\text { Level of air } \\
\text { impurity }(\mathrm{ppm})\end{array}$ & Discharge ignition & Discharge mode & $\begin{array}{c}\text { Discharge } \\
\text { current }\end{array}$ \\
\hline 1 & $0-55$ & No & --- & --- \\
\hline 2 & $55-225$ & Yes & Glow & Symmetric \\
\hline 3 & $225-1000$ & Yes & Glow & Non-symmetric \\
\hline 4 & $1000-1500$ & No & --- & --- \\
\hline
\end{tabular}

Before proceeding with the analysis of Table 4, it was considered necessary to describe in detail the main processes that occur in the discharge gap over a voltage cycle. This will help us thereafter in the interpretation of the results presented in Table 4. In order to simplify the analysis, the case of $150 \mathrm{ppm}$ air was chosen, as it exhibits symmetric characteristics.

\subsubsection{0 ppm level of air impurity:}

As can be seen from Table 4, for the $150 \mathrm{ppm}$ concentration of dry air, the discharge exhibits the characteristics of the glow mode and the discharge current is symmetric. The dominant positive and negative species are $\mathrm{O}_{2}{ }^{+}$and electrons respectively, as it will be demonstrated below. In glow-like discharges, the concentration of dominant ions reaches its maximum value near the cathode $\left(\sim 10^{17} 1 / \mathrm{m}^{3}\right)$, thus disturbing the electric field [11]. With this in mind, the spatio-temporal concentration of the $\mathrm{O}_{2}{ }^{+}$and electrons, and the absolute magnitude of the electric field are presented in Figure 3, together with the applied voltage, gap voltage and discharge current. It is noted that the vertical axis in Figure $3 b-3 d$ represents the spatial position across the parallel plate barrier discharge. In the simulation, the voltage is applied at the $6.4 \mathrm{~mm}$ point, while the point at $0 \mathrm{~mm}$ is grounded. Consequently, for positive polarity of the applied voltage, the $6.4 \mathrm{~mm}$ point represents the anode while the $0 \mathrm{~mm}$ point the cathode. The polarity of the applied voltage is illustrated on the graph.

From Figure 3a, it is observed that two individual breakdown events occur during the voltage cycle, with a single current peak per half period. The first breakdown occurs during the falling part of the applied voltage, while the second breakdown occurs during the rising part of the applied voltage. These breakdown events are a result of the voltage increase in the gap. As displayed in Figure 3a, the gap voltage follows a pattern similar to the applied voltage and reaches its maximum value at the time of breakdown. After the breakdown, the gap voltage is reduced and approaches zero because of the surface charge accumulation on the dielectrics, which shields the electric field of the applied voltage. For this reason, a single current peak is observed at each breakdown event. The symmetric characteristics of the discharge are evident from the same behaviour and absolute magnitude of the discharge current during both breakdown events. The opposite sign of the discharge current arises from the inversion of the voltage polarity. On the other hand, evidence of the glow-like discharge, is the maximum values attained by the electrons and the $\mathrm{O}_{2}{ }^{+}$(dominant ions in the mixture) near the cathode during the breakdown events (see Figure $3 \mathrm{~b}$ and Figure $3 \mathrm{c}$ ). This high concentration of ions disturbs the electric field near the cathode (Figure 3d), which is also a characteristic of the glow mode $[11,78]$. 


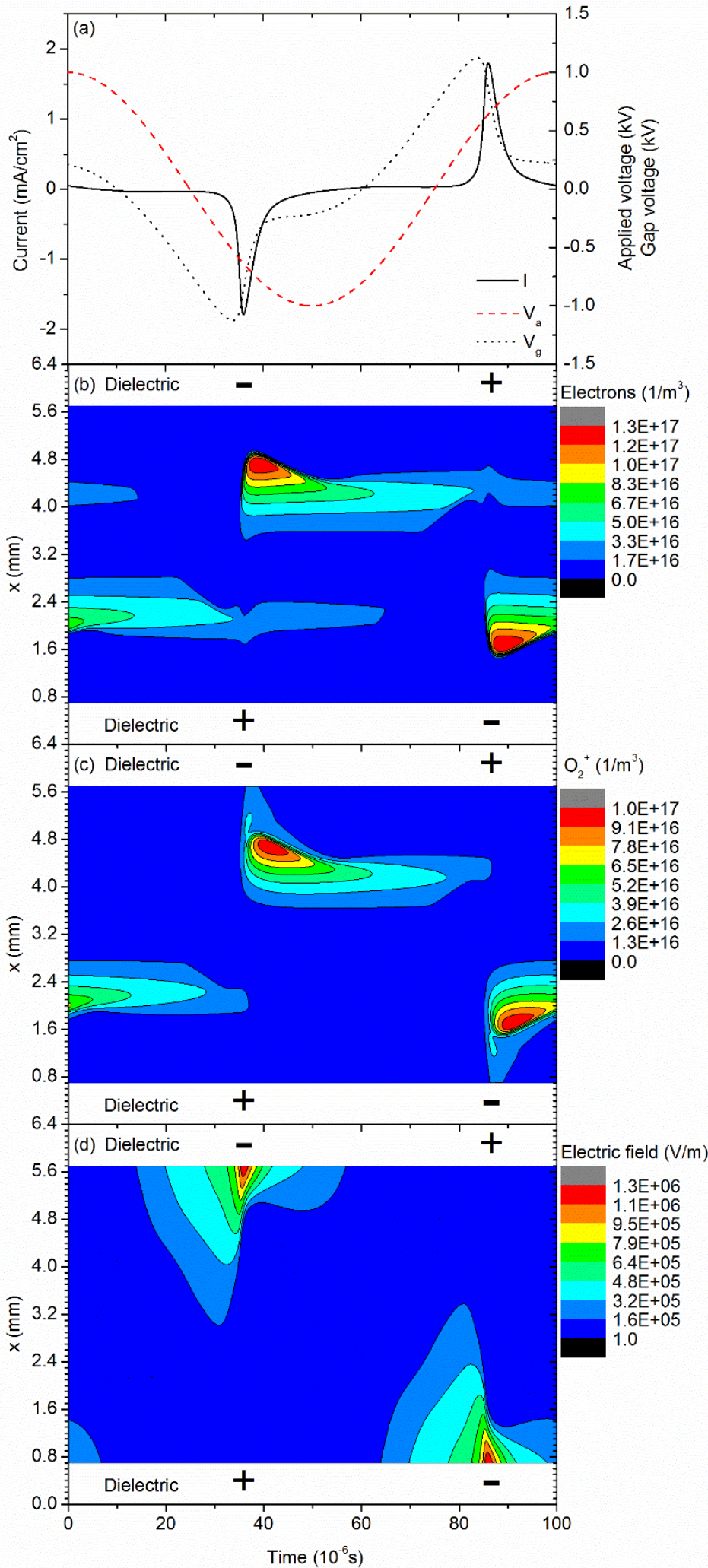

Figure 3: Simulation results of (a) the applied voltage, gap voltage and discharge current, and (b-d) the spatially-temporally resolved density distribution of electrons, $\mathrm{O}_{2}{ }^{+}$and absolute magnitude of the electric field respectively $(150 \mathrm{ppm})$, over a voltage cycle. The amplitude and frequency of the applied voltage are $1 \mathrm{kV}$ and $10 \mathrm{kHz}$ respectively.

In order to further understand the physics behind the discharge event, the evolution of positive and negative ions in the mixture during a voltage cycle is further analysed. Initially the 
positive ions are investigated. The average concentration of positive ions during a voltage cycle is captured in Figure 4, together with the applied voltage, gap voltage, electron temperature and discharge current. As shown in Figure 4, the concentration of ions is increased during the increase in the electron temperature. After the breakdown events, the ion concentrations are mostly reduced because of the reduction of the electron temperature. It is noted that the electron temperature follows a pattern similar to the absolute value of the gap voltage [27].

Figure $4 \mathrm{~b}$ clearly indicates that the most important positive ion in the mixture is $\mathrm{O}_{2}{ }^{+}$. This proves that even a weak concentration of impurity has a great influence on plasma composition, despite the much higher concentration of helium in the mixture. In comparison to $\mathrm{O}_{2}{ }^{+}$, the density of $\mathrm{O}_{4}{ }^{+}$is lower and remains almost constant between the two consecutive breakdowns. On the other hand, the nitrogen ions $\left(\mathrm{N}_{2}{ }^{+}\right.$and $\left.\mathrm{N}_{4}{ }^{+}\right)$are not as important as $\mathrm{O}_{2}{ }^{+}$, despite the higher concentration of nitrogen molecules in the air. Regarding the helium ions $\left(\mathrm{He}^{+}\right.$and $\left.\mathrm{He}_{2}^{+}\right)$, these have negligible densities compared to the nitrogen and oxygen ions during the breakdown events.

In order to shed more light into the processes that affect the evolution of ions, the most important processes of dominant positive ion $\left(\mathrm{O}_{2}{ }^{+}\right)$production and destruction in the mixture are presented in Figure 5. The criterion used for choosing the production and destruction processes was to have a maximum value higher than $8 \cdot 10^{-5}$ and $4 \cdot 10^{-5}\left[\mathrm{~mol} / \mathrm{m}^{3} \mathrm{~s}\right]$ respectively. Reactions with lower maximum values compared to the mentioned ones appear not to affect the simulation results and hence their choice as thresholds.

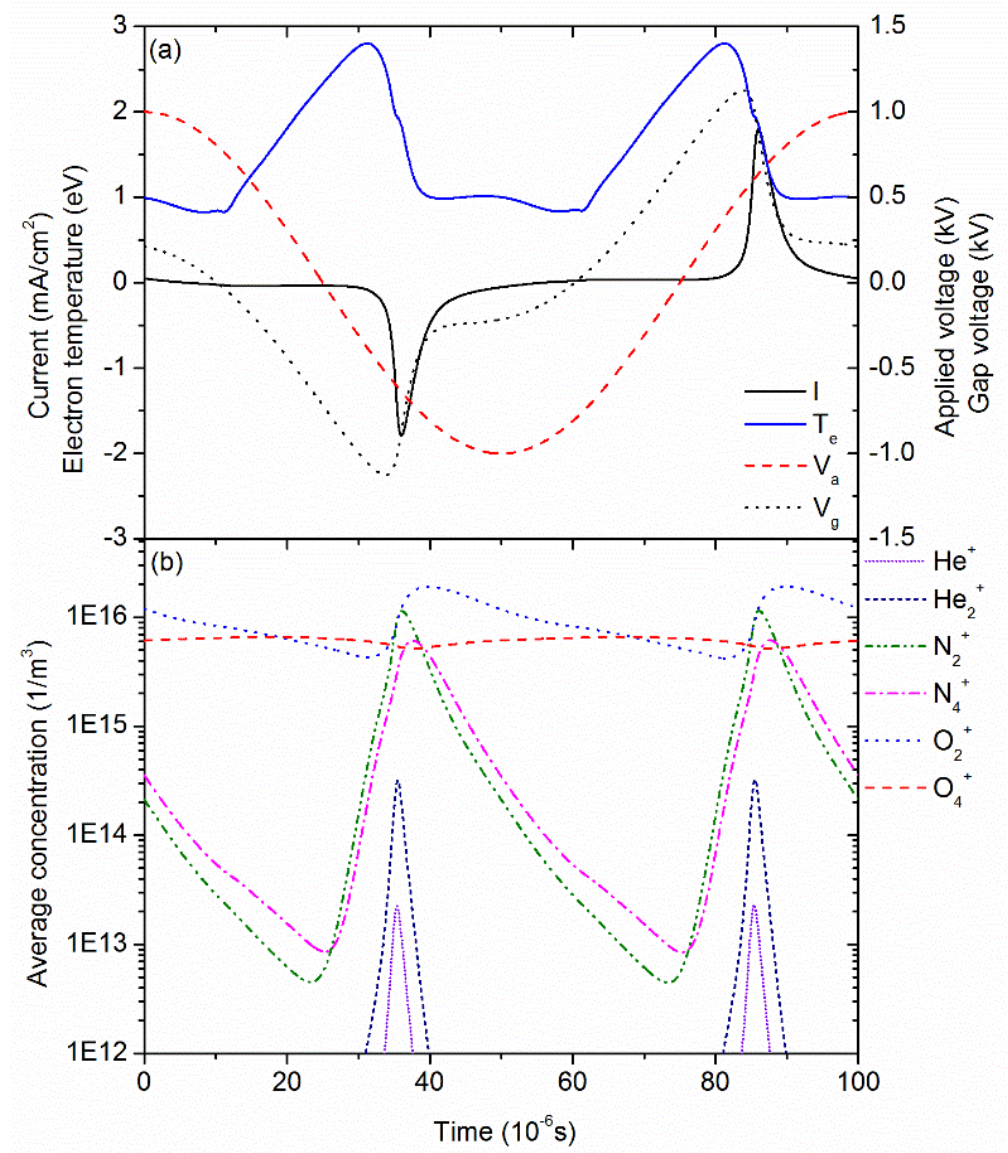

Figure 4: Simulation results of (a) the applied voltage, gap voltage, discharge current and average electron temperature, and (b) the average concentration of positive ion species for a He-air mixture $(150 \mathrm{ppm})$ over a voltage cycle. The amplitude and frequency of the applied voltage are $1 \mathrm{kV}$ and $10 \mathrm{kHz}$ respectively. 
From Figure 5a, it can be seen that the Penning ionization $\left(\mathrm{He}_{\mathrm{m}}+\mathrm{O}_{2}=>\mathrm{O}_{2}{ }^{+}+\mathrm{He}+\mathrm{e}^{-}\right.$, $\mathrm{R} 107)$ of $\mathrm{O}_{2}$ by $\mathrm{He}_{\mathrm{m}}$ is the most important reaction for $\mathrm{O}_{2}{ }^{+}$production. The remaining important reactions for $\mathrm{O}_{2}{ }^{+}$production are more than one order of magnitude lower. These processes are the Penning ionization of $\mathrm{O}_{2}$ by $\mathrm{He}_{2} *\left(\mathrm{He}_{2}{ }^{*}+\mathrm{O}_{2}=>\mathrm{O}_{2}{ }^{+}+2 \mathrm{He}+\mathrm{e}^{-}, \mathrm{R} 108\right)$, the direct ionization of ground state $\mathrm{O}_{2}$ molecules $\left(\mathrm{e}+\mathrm{O}_{2}=>2 \mathrm{e}+\mathrm{O}_{2}{ }^{+}\right.$, R74) and the charge transfer reactions $\left(\mathrm{He}_{2}{ }^{+}+\mathrm{O}_{2}=>2 \mathrm{He}+\mathrm{O}_{2}{ }^{+}, \mathrm{N}_{2}{ }^{+}+\mathrm{O}_{2}=>\mathrm{N}_{2}+\mathrm{O}_{2}{ }^{+}\right.$and $\mathrm{N}_{4}{ }^{+}+\mathrm{O}_{2}=>2 \mathrm{~N}_{2}+\mathrm{O}_{2}{ }^{+} \mathrm{R} 110, \mathrm{R} 134$ and R135 respectively) associated with the helium and nitrogen ions. This also explains the lower concentration of helium and nitrogen ions $\left(\mathrm{He}_{2}{ }^{+}, \mathrm{N}_{2}{ }^{+}\right.$and $\left.\mathrm{N}_{4}{ }^{+}\right)$during the breakdown events (see Figure $4 \mathrm{~b}$ ), as they are converted to oxygen ions.

Our calculations show that the destruction of $\mathrm{O}_{2}{ }^{+}$is almost completely determined by the losses at the boundaries (B1 and B2, see Figure 5b). B1 and B2 refer to the dielectric layers which cover the ground contact and the contact of the applied voltage respectively. On the contrary, the loss of $\mathrm{O}_{2}{ }^{+}$due to volume processes is more than one order of magnitude lower. From these processes, the three-body charge transfer reaction $\left(\mathrm{O}_{2}{ }^{+}+\mathrm{O}_{2}+\mathrm{He}=>\mathrm{O}_{4}{ }^{+}+\mathrm{He}, \mathrm{R} 106\right)$ is the most important. Other loss processes are determined by the recombination of $\mathrm{O}_{2}{ }^{+}$with electrons $\left(\mathrm{e}^{-}+\mathrm{O}_{2}{ }^{+}=>2 \mathrm{O}, \mathrm{R} 75\right)$ and with $\mathrm{O}_{2}^{-}\left(\mathrm{O}_{2}{ }^{+}+\mathrm{O}_{2}{ }^{-}+\mathrm{He}=>2 \mathrm{O}_{2}+\mathrm{He}, \mathrm{R} 113\right)$.

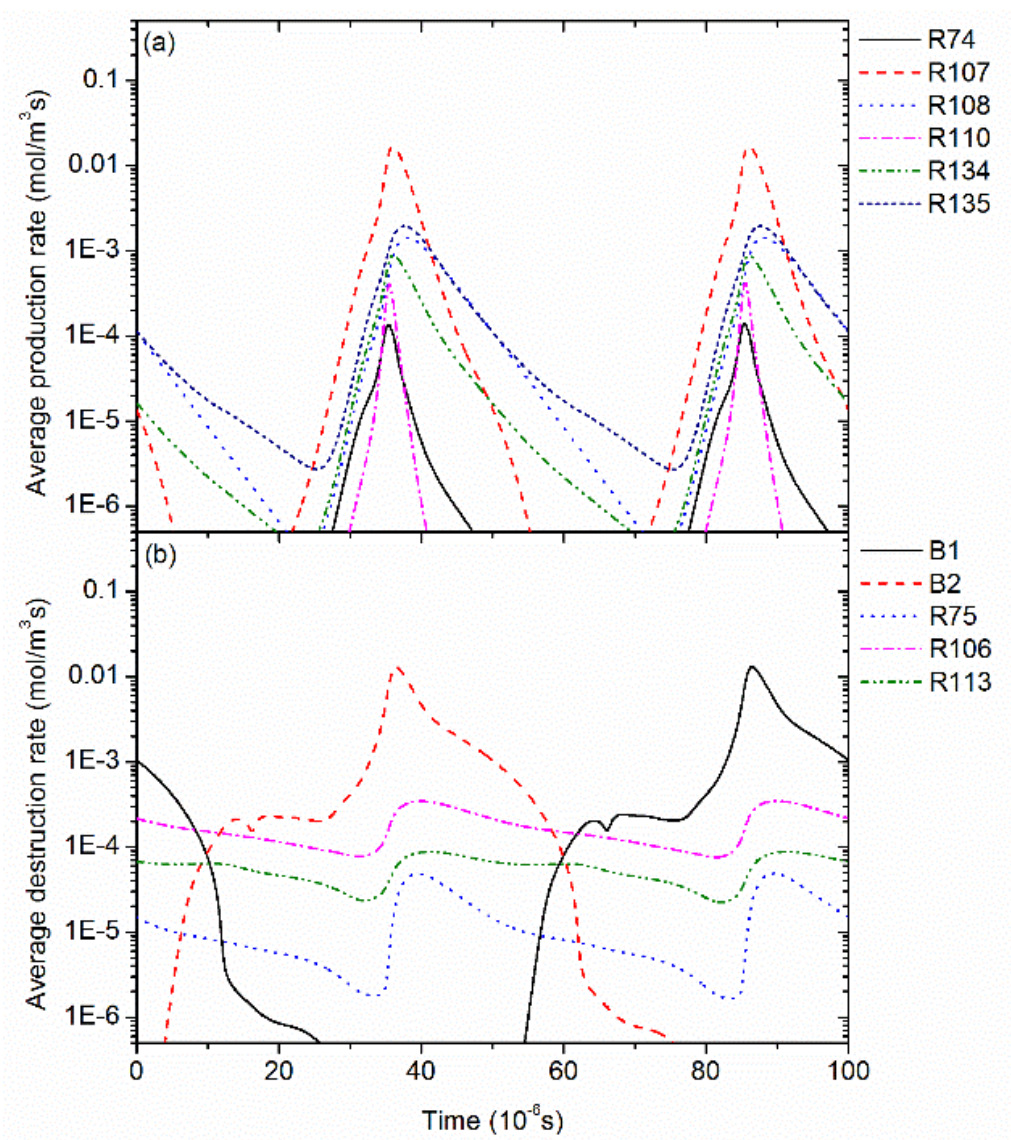

Figure 5: Simulation of the average rates for (a) production and (b) destruction of $\mathrm{O}_{2}{ }^{+}$as a function of time for $150 \mathrm{ppm}$ dry air. 


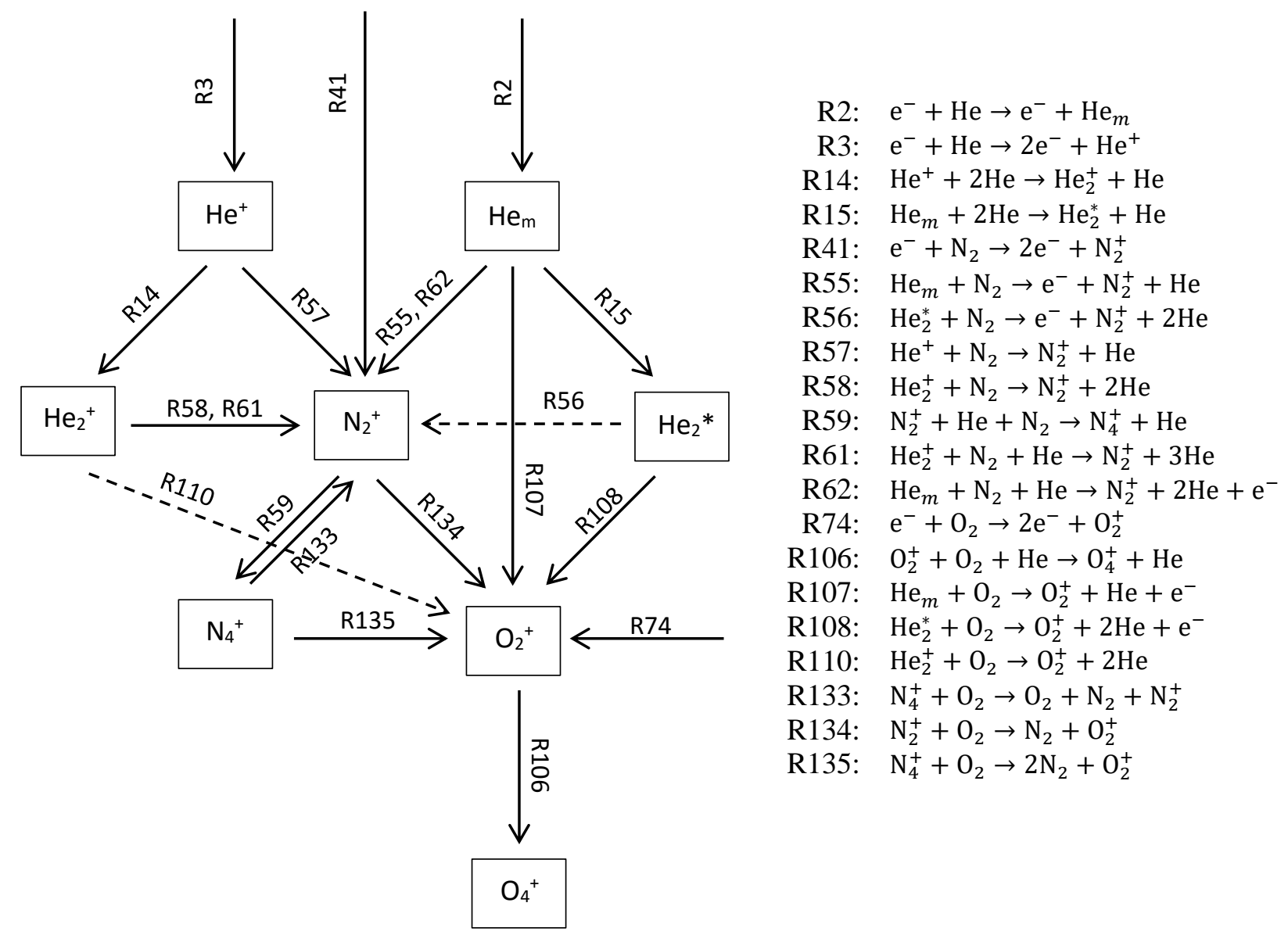

Figure 6: Schematic diagram of the most important reaction pathways for ion production.

In order to elucidate the underlying mechanisms responsible for the above results, the most important reaction pathways for ion production are presented in Figure 6. As illustrated in the schematic diagram, the increase of ion densities is almost completely determined by the increase of $\mathrm{He}_{\mathrm{m}}$ and $\mathrm{He}^{+}$. The concentration of the former species is increased during the increase of the electron temperature (see Figure 4a). After the breakdown, the production of $\mathrm{He}_{\mathrm{m}}$ and $\mathrm{He}^{+}$is reduced because of the low electron temperature.

From Figure 6, it can be seen that the helium metastable atoms $\left(\mathrm{He}_{\mathrm{m}}\right)$ are mainly deexcited by producing $\mathrm{He}_{2}{ }^{*}, \mathrm{~N}_{2}{ }^{+}$and $\mathrm{O}_{2}{ }^{+}$through reactions 15, 55, 62 and 107. After that, $\mathrm{He}_{2}{ }^{*}$ is decomposed during the production of $\mathrm{N}_{2}{ }^{+}$and $\mathrm{O}_{2}{ }^{+}$through the Penning reactions 56 and 108 respectively. On the other hand, the $\mathrm{He}^{+}$ions are immediately converted to $\mathrm{He}_{2}{ }^{+}$and $\mathrm{N}_{2}{ }^{+}$ through the charge conversion reaction 14 and the charge transfer reaction 57 respectively. This explains the reason of the low concentration of $\mathrm{He}^{+}$during the breakdown. Moreover, the low concentration of $\mathrm{He}_{2}{ }^{+}$at breakdown events is attributed to its fast conversion to $\mathrm{N}_{2}{ }^{+}$and $\mathrm{O}_{2}{ }^{+}$ through reactions 58, 61 and 110 .

The above processes increase the concentration of $\mathrm{N}_{2}{ }^{+}$and $\mathrm{O}_{2}{ }^{+}$in the mixture. As shown in the schematic diagram, the $\mathrm{N}_{2}{ }^{+}$is mainly converted to $\mathrm{N}_{4}{ }^{+}$and $\mathrm{O}_{2}{ }^{+}$through the charge conversion reaction 59 and the charge transfer reaction 134. Subsequently, the $\mathrm{N}_{4}{ }^{+}$is converted to $\mathrm{N}_{2}{ }^{+}$and $\mathrm{O}_{2}{ }^{+}$through the linked reactions 133 and 135 respectively. It is also noted that $\mathrm{N}_{2}{ }^{+}$ and $\mathrm{O}_{2}{ }^{+}$are produced from direct ionization of the ground state nitrogen and oxygen molecules (reactions 41 and 74). However, the former reactions are not the main source of $\mathrm{N}_{2}{ }^{+}$and $\mathrm{O}_{2}{ }^{+}$ 
production, for the range of air concentration considered in this study. Finally, the $\mathrm{O}_{4}{ }^{+}$is created from the charge transfer of $\mathrm{O}_{2}{ }^{+}$, reaction 106.

The above discussion highlights the processes behind ion production during the increase of the gap voltage and clearly shows that finally the oxygen ions survive. Although the $\mathrm{O}_{2}{ }^{+}$is finally converted to $\mathrm{O}_{4}{ }^{+}$in the range of concentrations considered in this study, the rate of this conversion is small and thus $\mathrm{O}_{2}{ }^{+}$remains the dominant ion in the mixture. This was also observed from the global model [28].

At this point, it is also worth analyzing the negative ions in the mixture. The concentration of the negative ions over a voltage cycle is presented in Figure 7 together with the applied voltage and discharge current. Figure $7 \mathrm{~b}$ shows that the electrons are the dominant negative species in the mixture. In contrast, the negative oxygen ions have negligible concentration during the voltage cycle. These have densities more than two orders of magnitude lower than the electron density. In order to further analyse the negative ions, the most important processes for the production and destruction of the dominant negative ions in the mixture (electrons) are presented in Figure 8. The criterion for the chosen production and destruction processes was to have a maximum value higher than $8 \cdot 10^{-5}$ and $4 \cdot 10^{-5}\left[\mathrm{~mol} / \mathrm{m}^{3} \mathrm{~s}\right]$ respectively for the reasons explained earlier.

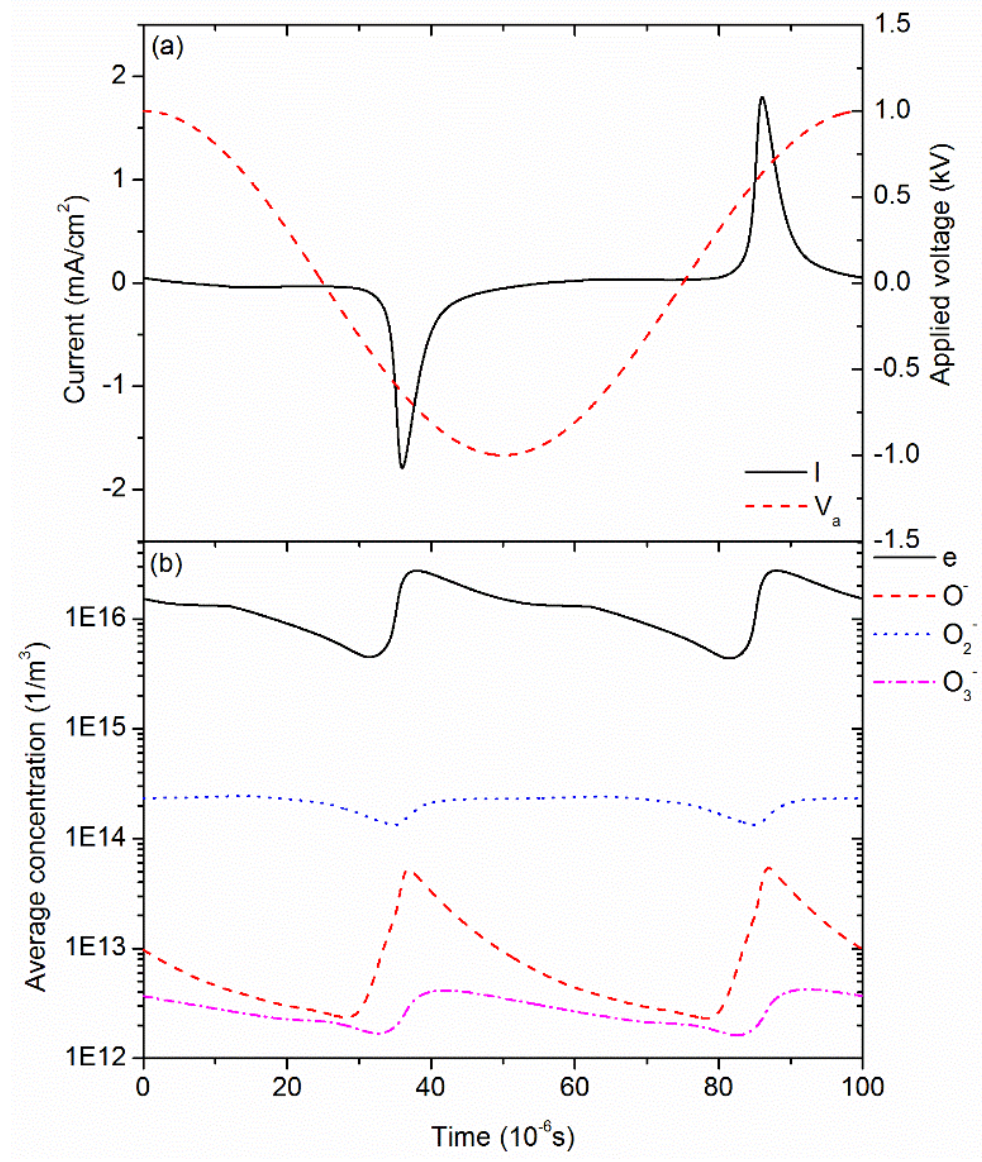

Figure 7: Simulation result of (a) the applied voltage and discharge current, and (b) the average concentration of negative ion species for a He-air mixture $(150 \mathrm{ppm})$ over a voltage cycle. The amplitude and frequency of the applied voltage are $1 \mathrm{kV}$ and $10 \mathrm{kHz}$ respectively.

Figure 8a shows that the Penning ionization of nitrogen and oxygen molecules by helium metastable atoms (R55, R62 and R107) constitute the most important reactions for electron production during breakdown. Additional important reactions are the direct ionization 
of helium atoms $\left(\mathrm{e}^{-}+\mathrm{He}=>2 \mathrm{e}^{-}+\mathrm{He}^{+}, \mathrm{R} 3\right)$, and the Penning ionization of nitrogen and oxygen molecules by helium dimmers (R56 and R108). It is important to note that the production of electrons during the afterglow stage is completely determined by the Penning ionization of $\mathrm{N}_{2}$ and $\mathrm{O}_{2}$ by $\mathrm{He}_{2}{ }^{*}$. A smaller contribution towards electron production is provided by the direct ionization of ground state nitrogen and oxygen molecules, reaction 41 and 74 respectively. The above results are in agreement with the schematic diagram presented in Figure 6.

As in the case of $\mathrm{O}_{2}{ }^{+}$(the dominant positive ions), the loss at the boundaries is the dominant mechanism for the destruction of electrons (see Figure $8 b$ ). In comparison to surface processes, electron destruction due to volume processes is not as important. Nonetheless, these reactions are the recombination of electrons with $\mathrm{N}_{2}{ }^{+}, \mathrm{N}_{4}{ }^{+}, \mathrm{O}_{2}{ }^{+}$and $\mathrm{O}_{4}{ }^{+}(\mathrm{R} 43, \mathrm{R} 46, \mathrm{R} 75$ and R95) and the two and three-body electron attachment with oxygen molecules (R64 and R105). Up to this point, the most important processes that occur in the discharge gap have been analyzed. Furthermore, the reaction pathways presented in the schematic diagram of Figure 6 hold for the range of air concentration considered in this study. However, there is no insight regarding the effect of air on the magnitude of the rate of these reactions.

In order to complete the picture of the analysis and proceed towards the analysis of Table 4, it was deemed necessary to provide an insight into the effect of the air content on the most important reactions of ion production in the mixture (reactions of the schematic diagram of Figure 6). With this in mind, the magnitude of the peak of these reaction rates is captured in Figure 9 as a function of the concentration of air, together with the breakdown voltage. The results of the reactions were split into three groups based on the following criteria: production of ions through the reaction pathways associated with (a) helium ions, (b) helium metastable atoms and dimmers and (c) nitrogen and oxygen species. This analysis is presented only in the symmetric case where the magnitude of the reaction rates is the same during both breakdown events. 


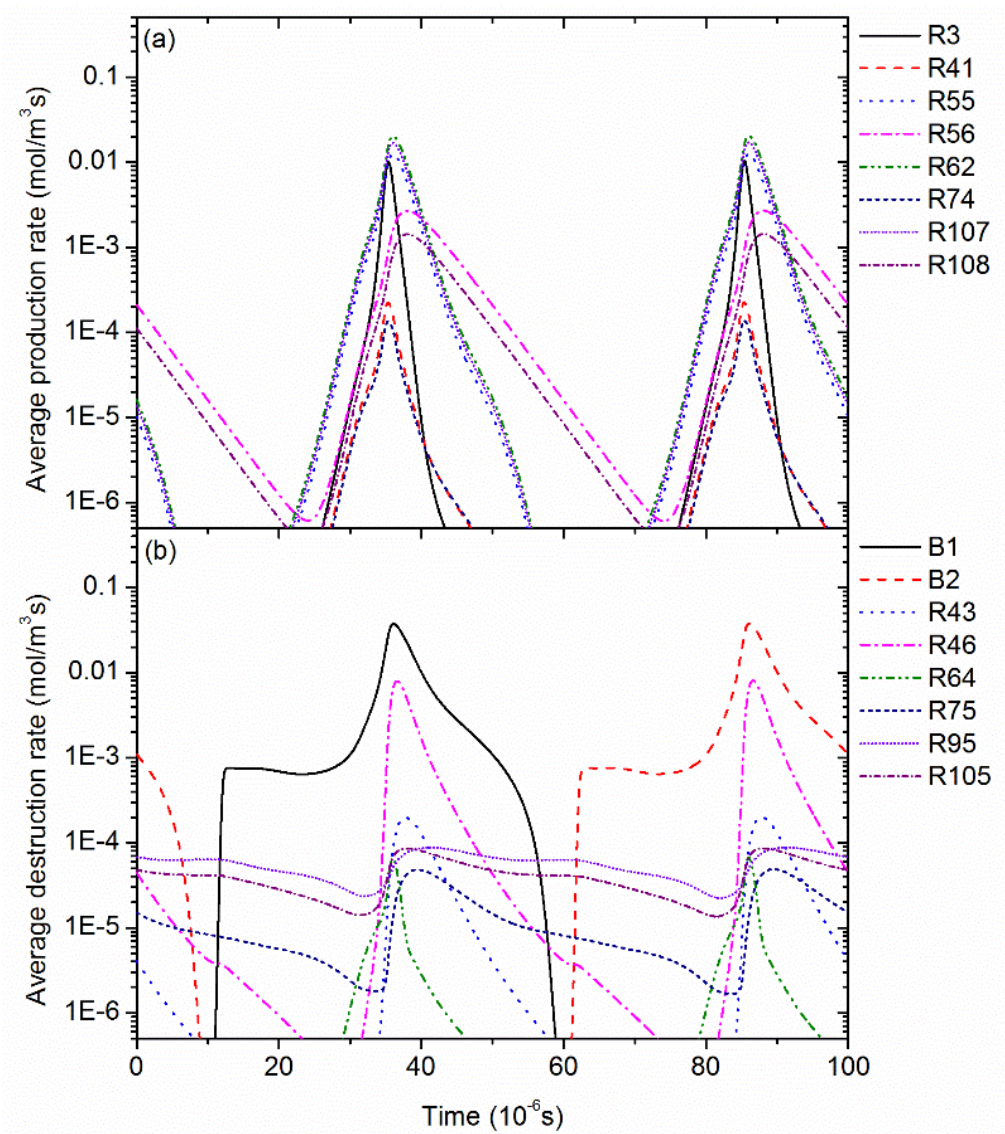

Figure 8: Simulation of the average rates for (a) production and (b) destruction of electrons as a function of time for $150 \mathrm{ppm}$ dry air.

\subsubsection{Effect of air concentration on the most important reactions for ion production.}

From the schematic diagram (see Figure 6) it has been proved that ion production is mainly governed by the increase in $\mathrm{He}_{\mathrm{m}}$ and $\mathrm{He}^{+}$in the mixture. For a constant concentration of air, the discharge is ignited when the $\mathrm{He}_{\mathrm{m}}$ and $\mathrm{He}^{+}$reach appropriate values for the production of adequate ions which are able to trigger breakdown. However, the increase in air concentration benefits the reactions associated with the ground state nitrogen and oxygen molecules (see reactions of the schematic diagram in Figure 6). As a result, a lower concentration of $\mathrm{He}_{\mathrm{m}}$ and $\mathrm{He}^{+}$is required for ion production. The concentration of the former species is highly dependent on the electron temperature and consequently on the gap voltage [27]. The lower the concentration of these species, the lower the breakdown voltage. 


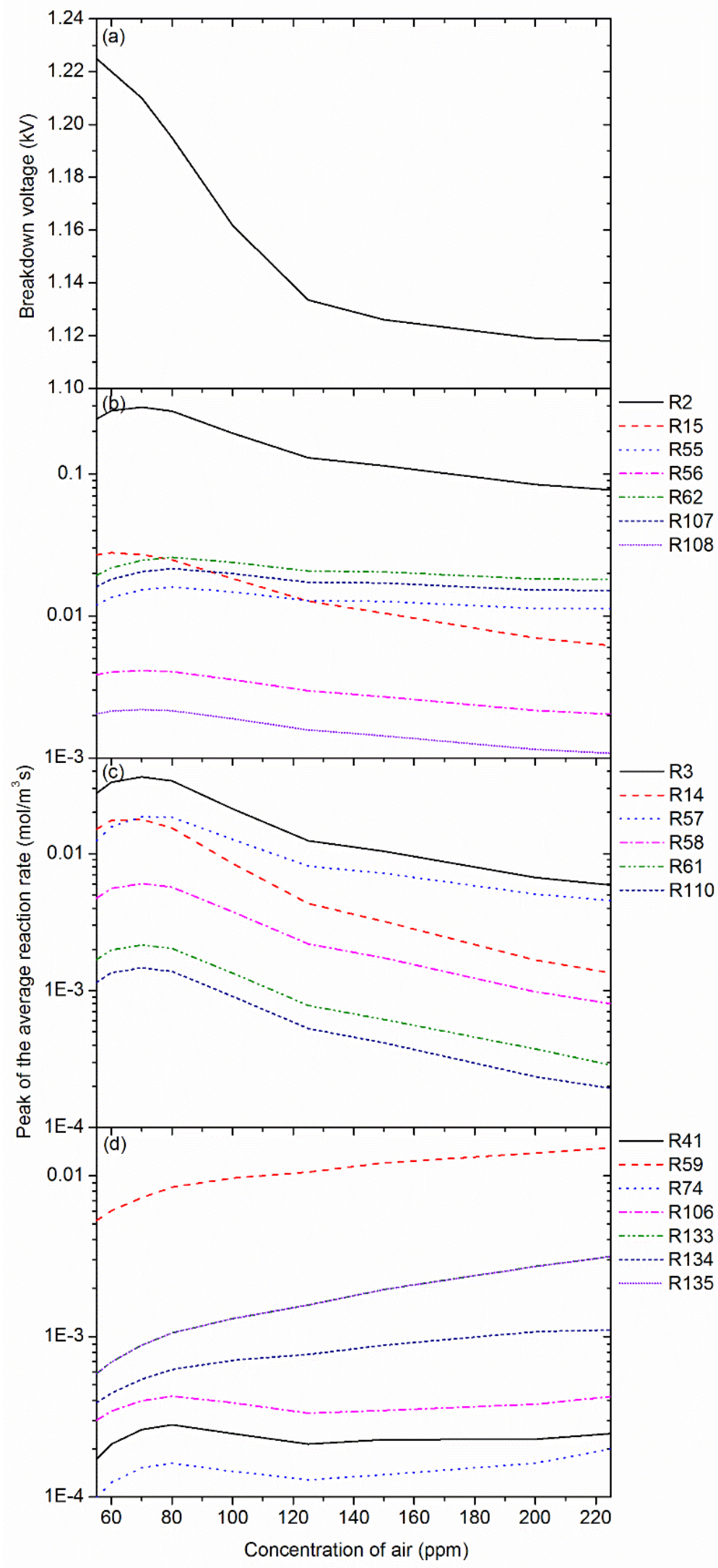

Figure 9: Simulated (a) breakdown voltage and (b-d) peak of the average reaction rates as a function of the concentration of air. The amplitude and frequency of the applied voltage are 1 $\mathrm{kV}$ and $10 \mathrm{kHz}$ respectively. 
The decrease in the breakdown voltage and the production rates of $\mathrm{He}_{\mathrm{m}}$ and $\mathrm{He}^{+}(\mathrm{R} 2$ and R3) as the concentration of air increases in the mixture are clearly depicted in Figure 9a9c. In the range between 55 and $70 \mathrm{ppm}$, however, an increase in the reaction rates is observed. This is attributed to the increase in the production rate of electrons, due to the increase in air concentration in the mixture. As a result, despite lower breakdown voltage and thus lower coefficient rate of reactions 2 and 3, the higher concentration of electrons increases the rate of these reactions. Beyond $80 \mathrm{ppm}$ of air, the rate of electron production is reduced for the reasons that will be explained below.

Initially, the production of ions through the reaction pathways associated with the helium metastable atoms is analyzed. The $\mathrm{He}_{\mathrm{m}}$ mainly produces $\mathrm{He}_{2}{ }^{*}, \mathrm{~N}_{2}{ }^{+}$and $\mathrm{O}_{2}{ }^{+}$through reaction pathways R15, R55, R62 and R107 (see Figure 6). Furthermore, the $\mathrm{He}_{2}{ }^{*}$ decomposes and produces $\mathrm{N}_{2}{ }^{+}$and $\mathrm{O}_{2}{ }^{+}$through the linked reactions 56 and 108 respectively. As shown in Figure 9a, the production of $\mathrm{N}_{2}{ }^{+}$and $\mathrm{O}_{2}{ }^{+}$through reaction pathways linked to $\mathrm{He}_{\mathrm{m}}$ and $\mathrm{He}_{2}$ * (R55, R56, R62, R107 and R108) mostly decreases, with the exception at low air concentration (up to 70-80 ppm). As expected, these reaction rates follow a pattern similar to the production rate of $\mathrm{He}_{\mathrm{m}}$. In the range from 80 to $225 \mathrm{ppm}$, the reactions R55, R62 and R107 experience a slower decrease because of the higher amount of $\mathrm{N}_{2}$ and $\mathrm{O}_{2}$ in the mixture, and consequently the higher amount of $\mathrm{He}_{\mathrm{m}}$ lost through these reactions. Moreover, the production of electrons is mainly governed by the reactions 55, 62 and 107 during the breakdown and the reactions 56 and 108 during the afterglow. These reactions decrease as the air concentration increases in the mixture, thus reducing the production rate of electrons.

The other important species responsible for the production of ions in the mixture is $\mathrm{He}^{+}$ (see Figure 6). The $\mathrm{He}^{+}$is mainly converted into $\mathrm{He}_{2}{ }^{+}$and $\mathrm{N}_{2}{ }^{+}$through reactions 14 and 57 respectively. Subsequently, the $\mathrm{He}_{2}{ }^{+}$is converted quickly into $\mathrm{N}_{2}{ }^{+}$and $\mathrm{O}_{2}{ }^{+}$through reactions 58, 61 and 110. From Figure 9c, it can be observed that the production rates of $\mathrm{N}_{2}{ }^{+}$and $\mathrm{O}_{2}{ }^{+}$ through the reaction pathways associated with the $\mathrm{He}^{+}$and $\mathrm{He}_{2}{ }^{+}(57,58,61$ and 110) experience an increase up to $70 \mathrm{ppm}$ and then they decrease for higher air concentration. This behaviour is similar to the production rate of $\mathrm{He}^{+}$. Furthermore, the rate of reaction 57 decreases more slowly (between 70-225 ppm), due to the increase in $\mathrm{N}_{2}$ in the mixture, and consequently the higher amount of $\mathrm{He}^{+}$lost in this reaction.

The reaction pathways associated with helium species $\left(\mathrm{He}_{\mathrm{m}}, \mathrm{He}^{+}, \mathrm{He}_{2}{ }^{*}\right.$ and $\left.\mathrm{He}_{2}{ }^{+}\right)$ increase the concentration of $\mathrm{N}_{2}{ }^{+}$and $\mathrm{O}_{2}{ }^{+}$in the mixture. From Figure 9d, it can be seen that the $\mathrm{N}_{2}{ }^{+}$is mostly converted into $\mathrm{N}_{4}^{+}$(R59), while a smaller concentration of $\mathrm{N}_{2}{ }^{+}$is lost through the production of $\mathrm{O}_{2}{ }^{+}$(R135). By increasing air concentration, the rate of the former reactions increases due to the higher concentration of $\mathrm{N}_{2} / \mathrm{O}_{2}$ in these reactions. Similar behaviour is demonstrated for the rate of reactions 133 and 135 for the production of $\mathrm{N}_{2}{ }^{+}$and $\mathrm{O}_{2}{ }^{+}$through $\mathrm{N}_{4}{ }^{+}$. On the other hand, the production rates of $\mathrm{N}_{2}{ }^{+}$and $\mathrm{O}_{2}{ }^{+}$through direct ionization show a peak at $\sim 80 \mathrm{ppm}$, and then they increase again for impurity levels higher than $125 \mathrm{ppm}$. The peak of these reaction rates is caused by the increase in the electron concentration (for the reasons already mentioned). On the other hand, the increase in the reaction rates for impurity levels higher than $125 \mathrm{ppm}$ is caused by the increase in $\mathrm{N}_{2}$ and $\mathrm{O}_{2}$ in the mixture (despite the lower breakdown voltage).

The production of $\mathrm{O}_{4}{ }^{+}$is only determined by reaction 106 . Consequently, the rate of this reaction, as expected has a similar trend to the sum of the production rates of $_{2}{ }^{+}(\mathrm{R} 74$, R107, R108, R110, R134 and R135). As can be seen from Figure 9d, the rate of reaction 106 follows a pattern similar to the rate of reaction 107 (most important reaction for $\mathrm{O}_{2}{ }^{+}$production) up to $125 \mathrm{ppm}$. For impurity levels higher than $125 \mathrm{ppm}$, the production rate of $\mathrm{O}_{4}{ }^{+}$experiences a small increase due to the increase in the production rate of $\mathrm{O}_{2}{ }^{+}(\mathrm{R} 134$ and $\mathrm{R} 135)$. 
In summary, the production of positive ions through the reaction pathways associated with the helium species is mostly reduced, while the production of positive ions through the nitrogen and oxygen species mostly increases as air concentration increases in the mixture. On the other hand, the production of electrons mostly decreases because these are governed by the reaction pathways associated with helium species. Furthermore, the production of $\mathrm{He}_{2}{ }^{*}$ and $\mathrm{He}_{2}{ }^{+}$(R15 and R14) is more affected by the increase in the impurities, indicating that at higher air concentrations these species will become unimportant.

Having in mind the above analysis and the most important processes that occur in the discharge gap over a voltage cycle, it is easy to interpret the results of Table 4, which consider the influence of air concentration on the discharge ignition and symmetry.

\subsubsection{Influence of air concentration on the discharge ignition and symmetry:}

0 to $55 \mathrm{ppm}$ : Our calculations show that in this range of air concentration, no breakdown occurs. This is attributed to the low ion production during the increase/decrease in the applied voltage. In order to ignite the breakdown in this range, the production rate of ions has to be increased. This can be achieved by increasing the applied voltage.

55 to $225 \mathrm{ppm}$ : Another way to increase the rate of ion production is by increasing the level of air impurities in the mixture. As shown in the previous section, this benefits the reactions of ion production associated with $\mathrm{N}_{2}$ and $\mathrm{O}_{2}$. As a result, at about $55 \mathrm{ppm}$ of air, the ions reach appropriate values to cause breakdown. The increase in air concentration between 55 and 225 ppm decreases the breakdown voltage (see Figure 9a), and thus the discharge ignites in this range.

Furthermore, the discharge exhibits symmetric characteristics because of the adequate concentration of electrons before each breakdown. From the previous section, it has been demonstrated that the most important reactions for electron production are 3, 55, 56, 62, 107 and 108. The rate of these reactions is mostly reduced as air concentration increases (see Figure $9 \mathrm{~b}-9 \mathrm{c})$ and for that reason, the concentration of electrons is reduced. Nonetheless, in this range of impurities, the electron concentration after breakdown is not low enough to require a higher gap voltage for the next breakdown.

225 to 1000 ppm: By increasing further the air concentration, the breakdown voltage is reduced and so are the production rates of electrons. This decreases the concentration of electrons and as a result the next breakdown requires higher gap voltage to ignite. For that reason, the discharge does not exhibit symmetric characteristics. To elucidate this phenomenon, the average concentration of ions over a voltage cycle is presented in Figure 10, together with the applied voltage, gap voltage and discharge current. For this analysis, the case of $500 \mathrm{ppm}$ of air was chosen. The results of Figure 10 are repeatable at each voltage cycle. 


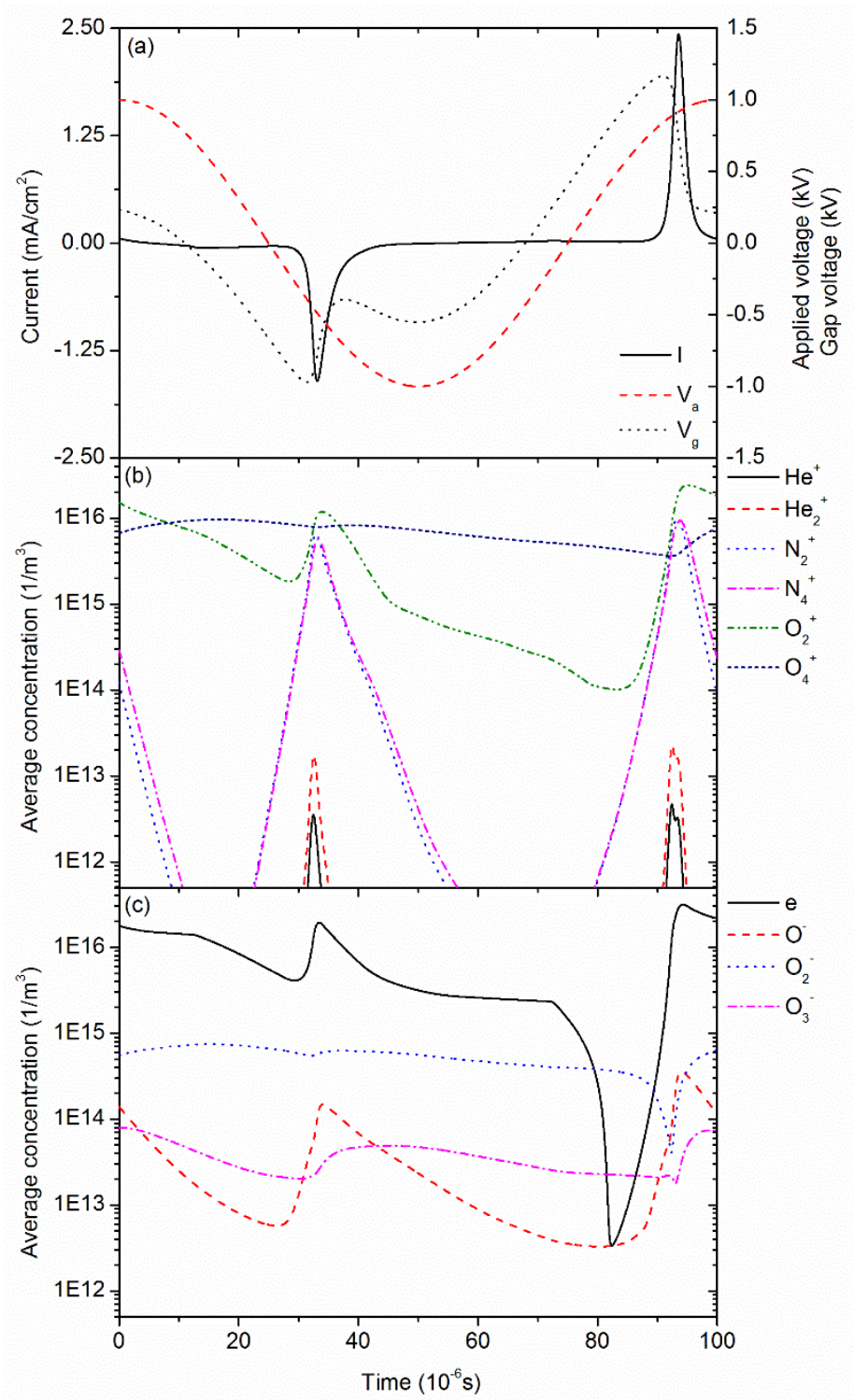

Figure 10: Simulation results of (a) the applied voltage, gap voltage and discharge current, (b) the average concentration of positive ion species, and (c) the average concentration of negative ion species for a He-air mixture $(500 \mathrm{ppm})$ over a voltage cycle. The amplitude and frequency of the applied voltage are $1 \mathrm{kV}$ and $10 \mathrm{kHz}$ respectively.

From Figure 10a, it is obvious that the discharge does not exhibit symmetric characteristics, as the magnitude of the discharge current is different during the falling and rising parts of the applied voltage. Additionally, the dominant positive and negative species during the breakdown events are $\mathrm{O}_{2}{ }^{+}$and electrons respectively (see Figure 10b and Figure 10c). In order to explain the reason for the discharge asymmetry, the concentration of electrons over a voltage cycle is further analyzed.

As illustrated in Figure 10c, the concentration of electrons is different before the first (during the falling part of the applied voltage) and the second breakdown (during the rising part of the applied voltage). In particular, the concentration of electrons is much lower before the second breakdown. This is attributed to the lower breakdown voltage of the first discharge $(0.97$ $\mathrm{kV})$ compared to the second breakdown $(1.17 \mathrm{kV})$, which results in lower electron production. As demonstrated in the previous section, the increase in air concentration in the mixture decreases the breakdown voltage and thus the first breakdown occurs at a lower gap voltage. 
The lower the breakdown voltage, the lower the production rates of $\mathrm{He}_{\mathrm{m}}$ and $\mathrm{He}^{+}$and thus of electrons (R3, R55, R56, R107 and R108). Consequently, the concentration of electrons before the second breakdown is lower. Furthermore, the concentration of electrons after the first breakdown is further reduced during the change of voltage polarity in the gap (loss of electrons at the boundaries). For the aforementioned reasons, the concentration of electrons before the second breakdown is reduced significantly as can be seen in Figure 10c. As a result, a higher gap voltage is required for the second breakdown to occur. After the second discharge, the concentration of electrons is not reduced significantly because of the higher breakdown voltage (see Figure 10c). This explains the asymmetry observed in the discharge current in Figure 10a.

In summary, the increase of air concentration in the mixture decreases the breakdown voltage and consequently the production rates of electrons. As a result, the concentration of electrons decreases after the breakdown and thus, a higher gap voltage is required to cause the next breakdown. In this range of air concentration, the applied voltage of $1 \mathrm{kV}$ is able to ignite the discharge even during the second breakdown event and so the discharge takes place during the falling and rising part of the applied voltage. Similar discharge asymmetries, during the increase in the $\mathrm{O}_{2}$ content in He DBD were also observed experimentally in [24].

1000 to $1500 \mathrm{ppm}$ : In this range of air impurities, the ignition of the discharge stops after a few voltage cycles. This is caused by the significant reduction of electrons after the breakdown and the low secondary emission flux. In order to examine this phenomenon, the average concentration of electrons is captured over some voltage cycles, together with the applied voltage, gap voltage, discharge current, surface charge density and secondary emission flux (see Figure 11). The results in Figure 11 correspond to the $4^{\text {th }}$ voltage cycle, and thereafter show the instance where the ignition of the discharge stops. For this analysis, the case of 1100 ppm for air concentration was chosen. Moreover, the symbols B1 and B2 in the graph refer to the surface (contacted with the plasma) of dielectric layers which cover the ground contact and the contact of the applied voltage respectively.

As illustrated in Figure 11a, the ignition of the discharge stops after the third breakdown event. This is due to the combined effect of low electron concentration and low surface charge density after the third breakdown event (see Figure 11b and Figure 11c). In particular, due to the low breakdown voltage of the third discharge event, the production rate of electrons is low and consequently their concentration remains low. This also affects the deposition of charge at the dielectrics. As it can be seen from Figure 11c, the accumulation of the charge at the dielectrics is lower after the third breakdown event in comparison with the previous discharges. Furthermore, the decrease in the surface charge density affects the secondary emission of electrons from the dielectrics. From Figure 11d, it is obvious that after the third breakdown event, the secondary emission flux is decreased. Consequently, due to the low concentration of electrons and the low secondary emission flux after the third breakdown event, the next discharge (during the rising part of the applied voltage) cannot be ignited. Moreover, as it can be seen from Figure 11b, the concentration of electrons after the first breakdown reaches lower values compared to the third one. However, the discharge is ignited after the first breakdown because of the higher surface charge density and consequently higher secondary emission flux.

Finally, in order to cause breakdown in this range, the applied voltage has to be increased. The need for the increase in the burning voltage due to the increase in the impurities content in the mixture was also observed experimentally [24]. 


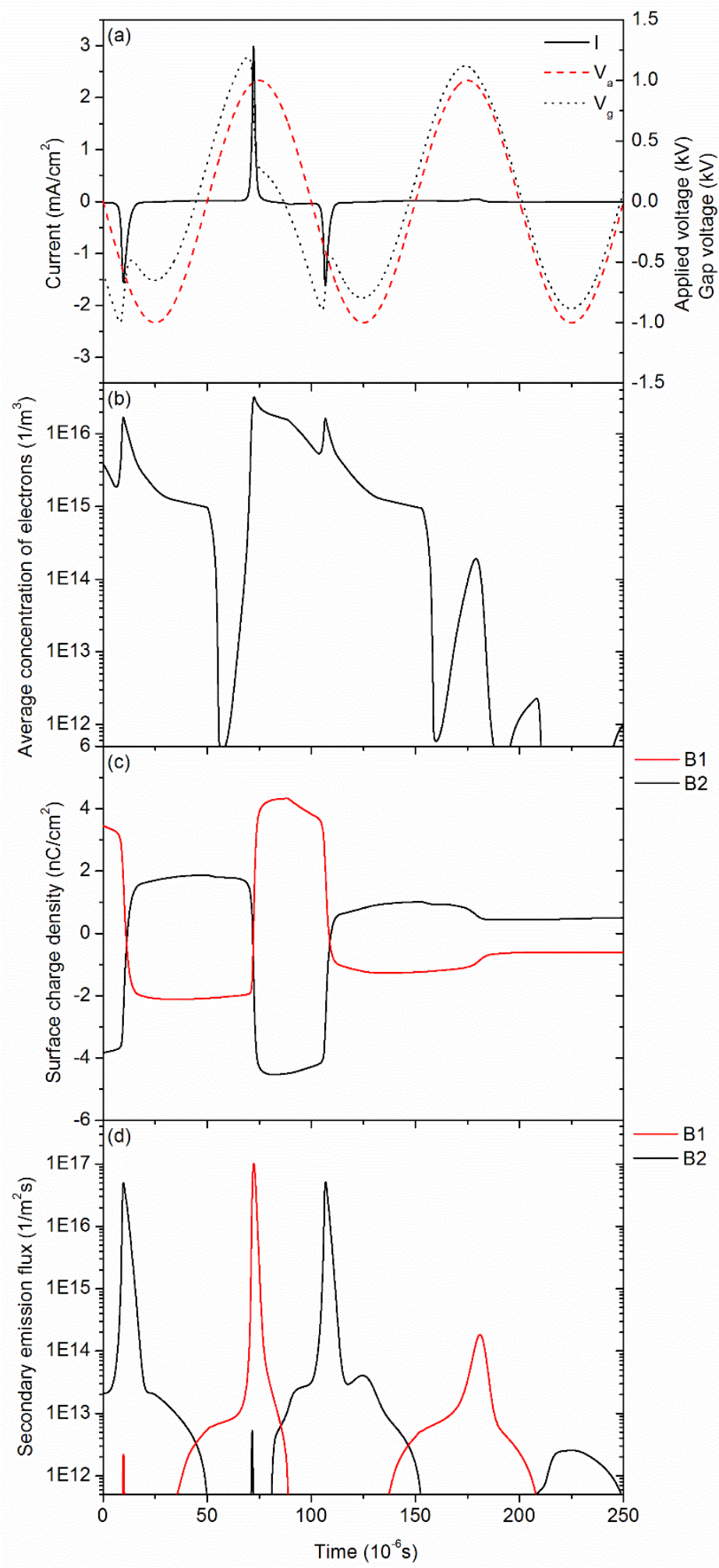

Figure 11: Simulation results of (a) the applied voltage, gap voltage and discharge current, (b) the average concentration of electrons, (c) the surface charge density, and (d) the secondary emission flux for a He-air mixture $(1100 \mathrm{ppm})$ over a voltage cycle. The amplitude and frequency of the applied voltage are $1 \mathrm{kV}$ and $10 \mathrm{kHz}$ respectively.

\section{Conclusion}

In this paper, a one dimensional model was used for the physical description of a helium barrier discharge with dry air impurities. This model takes into account 27 species and 151 
reaction channels. The heavy species (neutral, excited and ions) are described by the multicomponent-diffusion equation using the mixture-averaged diffusion coefficient. On the other hand, the electrons are described by the first three moments of the Boltzmann equation, which reduced after simplification to the continuity equation in the drift diffusion approximation. This model was validated with experimental results to ensure its correctness. Subsequently, the concentration of dry air considered as impurities, was varied in the range from 0 to $1500 \mathrm{ppm}$ in the numerical model, in order to investigate its effect on the discharge evolution, discharge ignition and discharge symmetry.

The calculations presented in this paper show that dry air significantly affects the helium-air plasma chemistry and consequently the discharge evolution. In particular, four different regions were observed based on the discharge ignition and discharge symmetry. It was observed that at low air concentration $(0-55 \mathrm{ppm})$, the discharge was not ignited due to the low amount of ions created during the increase/decrease of the applied voltage. As air concentration increases in the mixture, the production of ions through the reaction pathways associated with the ground state nitrogen and oxygen molecules benefit. For that reason, the breakdown voltage is reduced and thus the discharge is ignited in the range from 55 to $225 \mathrm{ppm}$. Furthermore, in this range, the discharge exhibits symmetric characteristics, due to the adequate concentration of electrons before each breakdown. By increasing the air concentration further, in the range from 225 to $1000 \mathrm{ppm}$, the discharge characteristics become asymmetric. This was caused by the decrease in the breakdown voltage and thus the production rate of electrons. As a result, after the breakdown, the electron concentration is reduced significantly and a higher gap voltage is required to ignite the next discharge. Furthermore, between 225 and $1000 \mathrm{ppm}$, the applied voltage of $1 \mathrm{kV}$ is able to trigger the breakdown, which requires higher gap voltage. For air concentration higher than $1000 \mathrm{ppm}$, the ignition of the discharge stops because the concentration of electrons is reduced to very low values after the breakdown and with the reduced secondary emission flux, the next breakdown cannot be ignited with the applied voltage of $1 \mathrm{kV}$. 
Appendix A.

\begin{tabular}{|c|c|c|c|c|}
\hline $\begin{array}{c}\text { Reaction } \\
\text { No. }\end{array}$ & Reaction equation ${ }^{a)}$ & Rate constant ${ }^{\text {b) }}$ & Threshold (eV) & Ref \\
\hline 1 & $\mathrm{e}^{-}+\mathrm{He} \rightarrow \mathrm{e}^{-}+\mathrm{He}$ & $f(\varepsilon)$ & 0 & [65] \\
\hline 2 & $\mathrm{e}^{-}+\mathrm{He} \rightarrow \mathrm{e}^{-}+\mathrm{He}_{m}$ & $f(\varepsilon)$ & 19.82 & [65] \\
\hline 3 & $\mathrm{e}^{-}+\mathrm{He} \rightarrow 2 \mathrm{e}^{-}+\mathrm{He}^{+}$ & $f(\varepsilon)$ & 24.58 & [65] \\
\hline 4 & $\mathrm{e}^{-}+\mathrm{He}_{m} \rightarrow 2 \mathrm{e}^{-}+\mathrm{He}^{+}$ & $f(\varepsilon)$ & 4.78 & [79] \\
\hline 5 & $\mathrm{e}^{-}+\mathrm{He}_{m} \rightarrow \mathrm{e}^{-}+\mathrm{He}$ & $2.9 \times 10^{-15}$ & -19.82 & {$[80,81]$} \\
\hline 6 & $\mathrm{e}^{-}+\mathrm{He}_{2}^{*} \rightarrow \mathrm{e}^{-}+2 \mathrm{He}$ & $3.8 \times 10^{-15}$ & -17.9 & {$[80]$} \\
\hline 7 & $2 \mathrm{e}^{-}+\mathrm{He}^{+} \rightarrow \mathrm{e}^{-}+\mathrm{He}_{m}$ & $7.8 \times 10^{-50}\left(T_{e} / T_{g}\right)^{-4.4}$ & -4.78 & [82] \\
\hline 8 & $2 \mathrm{e}^{-}+\mathrm{He}_{2}^{+} \rightarrow \mathrm{He}_{m}+\mathrm{He}+\mathrm{e}^{-}$ & $2.8 \times 10^{-32}$ & 0 & {$[80]$} \\
\hline 9 & $\mathrm{e}^{-}+\mathrm{He}+\mathrm{He}_{2}^{+} \rightarrow \mathrm{He}_{m}+2 \mathrm{He}$ & $3.5 \times 10^{-39}$ & 0 & [80] \\
\hline 10 & $2 \mathrm{e}^{-}+\mathrm{He}_{2}^{+} \rightarrow \mathrm{He}_{2}^{*}+\mathrm{e}^{-}$ & $1.2 \times 10^{-33}$ & 0 & [80] \\
\hline 11 & $\mathrm{e}^{-}+\mathrm{He}+\mathrm{He}_{2}^{+} \rightarrow \mathrm{He}_{2}+\mathrm{He}$ & $1.5 \times 10^{-39}$ & 0 & {$[80]$} \\
\hline 12 & $\mathrm{He}_{m}+\mathrm{He}_{m} \rightarrow \mathrm{He}_{2}^{+}+\mathrm{e}^{-}$ & $2.03 \times 10^{-15}\left(T_{g} / 300\right)^{0.5}$ & -18.2 & [83] \\
\hline 13 & $\mathrm{He}_{m}+\mathrm{He}_{m} \rightarrow \mathrm{He}^{+}+\mathrm{He}+\mathrm{e}^{-}$ & $8.7 \times 10^{-16}\left(T_{g} / 300\right)^{0.5}$ & -15.8 & [83] \\
\hline 14 & $\mathrm{He}^{+}+2 \mathrm{He} \rightarrow \mathrm{He}_{2}^{+}+\mathrm{He}$ & $1.4 \times 10^{-43}\left(T_{g} / 300\right)^{-0.6}$ & 0 & [83] \\
\hline 15 & $\mathrm{He}_{m}+2 \mathrm{He} \rightarrow \mathrm{He}_{2}^{*}+\mathrm{He}$ & $2 \times 10^{-46}$ & 0 & [83] \\
\hline 16 & $\mathrm{He}_{m}+\mathrm{He}_{2}^{*} \rightarrow \mathrm{He}^{+}+2 \mathrm{He}+\mathrm{e}^{-}$ & $5 \times 10^{-16}\left(T_{g} / 300\right)^{0.5}$ & -13.5 & [80] \\
\hline 17 & $\mathrm{He}_{m}+\mathrm{He}_{2}^{*} \rightarrow \mathrm{He}_{2}^{+}+\mathrm{He}+\mathrm{e}^{-}$ & $2 \times 10^{-15}\left(T_{g} / 300\right)^{0.5}$ & -15.9 & {$[80]$} \\
\hline 18 & $\mathrm{He}_{2}^{*}+\mathrm{He}_{2}^{*} \rightarrow \mathrm{He}^{+}+3 \mathrm{He}+\mathrm{e}^{-}$ & $3 \times 10^{-16}\left(T_{g} / 300\right)^{0.5}$ & -11.3 & {$[80]$} \\
\hline 19 & $\mathrm{He}_{2}^{*}+\mathrm{He}_{2}^{*} \rightarrow \mathrm{He}_{2}^{+}+2 \mathrm{He}+\mathrm{e}^{-}$ & $1.2 \times 10^{-15}\left(T_{g} / 300\right)^{0.5}$ & -13.7 & {$[80]$} \\
\hline 20 & $\mathrm{He}_{2}^{*}+\mathrm{He} \rightarrow 2 \mathrm{He}+\mathrm{He}$ & $1.5 \times 10^{-21}$ & 0 & {$[78,84]$} \\
\hline 21 & $\mathrm{e}^{-}+\mathrm{He}^{+} \rightarrow \mathrm{He}_{m}$ & $6.76 \times 10^{-19} T_{e}^{-0.5}$ & 0 & [85] \\
\hline 22 & $\mathrm{e}^{-}+\mathrm{He}+\mathrm{He}^{+} \rightarrow \mathrm{He}_{m}+\mathrm{He}$ & $7.4 \times 10^{-47}\left(T_{e} / T_{g}\right)^{-2}$ & 0 & [82] \\
\hline 23 & $\mathrm{e}^{-}+\mathrm{He}_{2}^{+} \rightarrow \mathrm{He}+\mathrm{He}_{m}$ & $7.12 \times 10^{-21}\left(T_{e} / T_{g}\right)^{-1.5}$ & 0 & {$[78]$} \\
\hline 24 & $\mathrm{e}^{-}+\mathrm{He}_{2}^{+} \rightarrow 2 \mathrm{He}$ & $1 \times 10^{-14}$ & 0 & [43] \\
\hline 25 & $\mathrm{e}^{-}+\mathrm{He}_{2}^{+}+\mathrm{He} \rightarrow 3 \mathrm{He}$ & $2 \times 10^{-39}$ & 0 & [43] \\
\hline 26 & $\mathrm{He}_{m}+2 \mathrm{He} \rightarrow 3 \mathrm{He}$ & $2 \times 10^{-46}$ & 0 & {$[78]$} \\
\hline 27 & $\mathrm{e}^{-}+\mathrm{He}_{2}^{*} \rightarrow \mathrm{He}_{2}^{+}+2 \mathrm{e}^{-}$ & $9.75 \times 10^{-16} T_{e}^{0.71} e^{-3.4 / T_{e}}$ & 3.4 & {$[83]$} \\
\hline 28 & $\mathrm{e}^{-}+\mathrm{N}_{2} \rightarrow 2 \mathrm{e}^{-}+\mathrm{N}_{2}(v=1$ to 10$)$ & $f(\varepsilon)$ & $\begin{array}{c}0.3,0.6,0.9,1.1 \\
1.4,1.7,2,2.2 \\
2.5,2.7\end{array}$ & {$[66]$} \\
\hline 29 & $\mathrm{e}^{-}+\mathrm{N}_{2} \rightarrow 2 \mathrm{e}^{-}+\mathrm{N}_{2}(\mathrm{~A})$ & $f(\varepsilon)$ & 6.2 & {$[66]$} \\
\hline 30 & $\mathrm{e}^{-}+\mathrm{N}_{2} \rightarrow 2 \mathrm{e}^{-}+\mathrm{N}_{2}(\mathrm{~A})$ & $f(\varepsilon)$ & 7 & {$[66]$} \\
\hline 31 & $\mathrm{e}^{-}+\mathrm{N}_{2} \rightarrow 2 \mathrm{e}^{-}+\mathrm{N}_{2}(\mathrm{~B})$ & $f(\varepsilon)$ & 7.4 & {$[66]$} \\
\hline 32 & $\mathrm{e}^{-}+\mathrm{N}_{2} \rightarrow 2 \mathrm{e}^{-}+\mathrm{N}_{2}(\mathrm{~B})$ & $f(\varepsilon)$ & 7.4 & {$[66]$} \\
\hline 33 & $\mathrm{e}^{-}+\mathrm{N}_{2} \rightarrow 2 \mathrm{e}^{-}+\mathrm{N}_{2}(\mathrm{~A})$ & $f(\varepsilon)$ & 7.8 & {$[66]$} \\
\hline 34 & $\mathrm{e}^{-}+\mathrm{N}_{2} \rightarrow 2 \mathrm{e}^{-}+\mathrm{N}_{2}(\mathrm{~B})$ & $f(\varepsilon)$ & 8.2 & {$[66]$} \\
\hline 35 & $\mathrm{e}^{-}+\mathrm{N}_{2} \rightarrow 2 \mathrm{e}^{-}+\mathrm{N}_{2}(\mathrm{a})$ & $f(\varepsilon)$ & 8.4 & {$[66]$} \\
\hline 36 & $\mathrm{e}^{-}+\mathrm{N}_{2} \rightarrow 2 \mathrm{e}^{-}+\mathrm{N}_{2}(\mathrm{a})$ & $f(\varepsilon)$ & 8.6 & {$[66]$} \\
\hline 37 & $\mathrm{e}^{-}+\mathrm{N}_{2} \rightarrow 2 \mathrm{e}^{-}+\mathrm{N}_{2}(\mathrm{a})$ & $f(\varepsilon)$ & 8.9 & {$[66]$} \\
\hline 38 & $\mathrm{e}^{-}+\mathrm{N}_{2} \rightarrow 2 \mathrm{e}^{-}+\mathrm{N}_{2}(\mathrm{C})$ & $f(\varepsilon)$ & 11 & {$[66]$} \\
\hline 39 & $\mathrm{e}^{-}+\mathrm{N}_{2} \rightarrow 2 \mathrm{e}^{-}+\mathrm{N}_{2}(\mathrm{C})$ & $f(\varepsilon)$ & 11.9 & {$[66]$} \\
\hline 40 & $\mathrm{e}^{-}+\mathrm{N}_{2} \rightarrow 2 \mathrm{e}^{-}+\mathrm{N}_{2}(\mathrm{C})$ & $f(\varepsilon)$ & 12.3 & {$[66]$} \\
\hline 41 & $\mathrm{e}^{-}+\mathrm{N}_{2} \rightarrow 2 \mathrm{e}^{-}+\mathrm{N}_{2}^{+}$ & $f(\varepsilon)$ & 15.5 & {$[66]$} \\
\hline
\end{tabular}




\begin{tabular}{|c|c|c|c|c|}
\hline 42 & $\mathrm{e}^{-}+\mathrm{N}_{2} \rightarrow \mathrm{e}^{-}+\mathrm{N}+\mathrm{N}$ & $1 \times 10^{-14} T_{e}^{0.5} e^{-16 / T_{e}}$ & 9.757 & [86] \\
\hline 43 & $\mathrm{e}^{-}+\mathrm{N}_{4}^{+} \rightarrow 2 \mathrm{~N}_{2}$ & $3 \times 10^{-13}$ & 0 & [87] \\
\hline 44 & $2 \mathrm{e}^{-}+\mathrm{N}_{4}^{+} \rightarrow 2 \mathrm{~N}_{2}+\mathrm{e}^{-}$ & $3.17 \times 10^{-42}$ & 0 & [38] \\
\hline 45 & $2 \mathrm{e}^{-}+\mathrm{N}_{2}^{+} \rightarrow \mathrm{e}^{-}+\mathrm{N}_{2}$ & $3.17 \times 10^{-42}$ & 0 & {$[71]$} \\
\hline 46 & $\mathrm{e}^{-}+\mathrm{N}_{2}^{+} \rightarrow 2 \mathrm{~N}$ & $4.8 \times 10^{-13}\left(T_{e} / T_{g}\right)^{-0.5}$ & 0 & [38] \\
\hline 47 & $\mathrm{~N}_{2}(\mathrm{~A})+\mathrm{N}_{2}(\mathrm{a}) \rightarrow \mathrm{e}^{-}+\mathrm{N}_{4}^{+}$ & $5 \times 10^{-17}$ & 0 & {$[52]$} \\
\hline 48 & $\mathrm{~N}_{2}(\mathrm{a})+\mathrm{N}_{2}(\mathrm{a}) \rightarrow \mathrm{e}^{-}+\mathrm{N}_{4}^{+}$ & $2 \times 10^{-16}$ & 0 & {$[52]$} \\
\hline 49 & $\mathrm{~N}_{2}(\mathrm{~B})+\mathrm{N}_{2} \rightarrow \mathrm{N}_{2}+\mathrm{N}_{2}(\mathrm{~A})$ & $3 \times 10^{-17}$ & 0 & {$[88]$} \\
\hline 50 & $\mathrm{~N}_{2}(\mathrm{C})+\mathrm{N}_{2} \rightarrow \mathrm{N}_{2}+\mathrm{N}_{2}(\mathrm{a})$ & $1 \times 10^{-17}$ & 0 & [88] \\
\hline 51 & $\mathrm{~N}_{2}(\mathrm{a}) \rightarrow \mathrm{N}_{2}+h v(117 \mathrm{~nm})$ & $1 \times 10^{2}$ & 0 & [89] \\
\hline 52 & $\mathrm{~N}_{2}(\mathrm{~A}) \rightarrow \mathrm{N}_{2}+h v(293 \mathrm{~nm})$ & 0.5 & 0 & [89] \\
\hline 53 & $\mathrm{~N}_{2}(\mathrm{~B}) \rightarrow \mathrm{N}_{2}(\mathrm{~A})+h v(1045 \mathrm{~nm})$ & $1.34 \times 10^{5}$ & 0 & [89] \\
\hline 54 & $\mathrm{~N}_{2}(\mathrm{C}) \rightarrow \mathrm{N}_{2}(\mathrm{~B})+h v(336 \mathrm{~nm})$ & $2.45 \times 10^{7}$ & 0 & [89] \\
\hline 55 & $\mathrm{He}_{m}+\mathrm{N}_{2} \rightarrow \mathrm{e}^{-}+\mathrm{N}_{2}^{+}+\mathrm{He}$ & $5 \times 10^{-17}$ & 0 & [38] \\
\hline 56 & $\mathrm{He}_{2}^{*}+\mathrm{N}_{2} \rightarrow \mathrm{e}^{-}+\mathrm{N}_{2}^{+}+2 \mathrm{He}$ & $5 \times 10^{-17}$ & 0 & [38] \\
\hline 57 & $\mathrm{He}^{+}+\mathrm{N}_{2} \rightarrow \mathrm{N}_{2}^{+}+\mathrm{He}$ & $6.5 \times 10^{-14}$ & 0 & [90] \\
\hline 58 & $\mathrm{He}_{2}^{+}+\mathrm{N}_{2} \rightarrow \mathrm{N}_{2}^{+}+2 \mathrm{He}$ & $1.1 \times 10^{-15}$ & 0 & {$[90]$} \\
\hline 59 & $\mathrm{~N}_{2}^{+}+\mathrm{He}+\mathrm{N}_{2} \rightarrow \mathrm{N}_{4}^{+}+\mathrm{He}$ & $8.9 \times 10^{-42}\left(T_{g} / 300\right)^{-1.54}$ & 0 & [90] \\
\hline 60 & $\mathrm{He}^{+}+\mathrm{N}_{2}+\mathrm{He} \rightarrow \mathrm{N}_{2}^{+}+2 \mathrm{He}$ & $1.1 \times 10^{-41}$ & 0 & [90] \\
\hline 61 & $\mathrm{He}_{2}^{+}+\mathrm{N}_{2}+\mathrm{He} \rightarrow \mathrm{N}_{2}^{+}+3 \mathrm{He}$ & $1.6 \times 10^{-41}$ & 0 & [90] \\
\hline 62 & $\mathrm{He}_{m}+\mathrm{N}_{2}+\mathrm{He} \rightarrow \mathrm{N}_{2}^{+}+2 \mathrm{He}+\mathrm{e}^{-}$ & $3.3 \times 10^{-42}$ & & [55] \\
\hline 63 & $\mathrm{e}^{-}+\mathrm{O}_{2} \rightarrow \mathrm{e}^{-}+\mathrm{O}_{2}(v=1$ to 4$)$ & $f(\varepsilon)$ & $\begin{array}{c}0.19,0.38,0.6 \\
0.8\end{array}$ & [66] \\
\hline 64 & $\mathrm{e}^{-}+\mathrm{O}_{2} \rightarrow \mathrm{O}+\mathrm{O}^{-}$ & $f(\varepsilon)$ & 0 & {$[66]$} \\
\hline 65 & $\mathrm{e}^{-}+\mathrm{O}_{2}(b) \rightarrow 0+\mathrm{O}^{-}$ & $f(\varepsilon)$ & 0 & [65] \\
\hline 66 & $\mathrm{e}^{-}+\mathrm{O}_{2}(a) \rightarrow \mathrm{O}+\mathrm{O}^{-}$ & $f(\varepsilon)$ & 0 & [65] \\
\hline 67 & $\mathrm{e}^{-}+\mathrm{O}_{2}(v) \rightarrow 0+\mathrm{O}^{-}$ & $f(\varepsilon)$ & 0 & {$[68]$} \\
\hline 68 & $\mathrm{e}^{-}+\mathrm{O}_{2} \rightarrow \mathrm{e}^{-}+\mathrm{O}_{2}(a)$ & $f(\varepsilon)$ & 0.977 & [66] \\
\hline 69 & $\mathrm{e}^{-}+\mathrm{O}_{2} \rightarrow \mathrm{e}^{-}+\mathrm{O}_{2}(b)$ & $f(\varepsilon)$ & 1.627 & [66] \\
\hline 70 & $\mathrm{e}^{-}+\mathrm{O} \rightarrow \mathrm{e}^{-}+\mathrm{O}\left({ }^{1} S\right)$ & $f(\varepsilon)$ & 4.192 & [65] \\
\hline 71 & $\mathrm{e}^{-}+\mathrm{O}_{2} \rightarrow \mathrm{e}^{-}+20$ & $f(\varepsilon)$ & 6 & [66] \\
\hline 72 & $\mathrm{e}^{-}+\mathrm{O}_{2} \rightarrow \mathrm{e}^{-}+\mathrm{O}+\mathrm{O}\left({ }^{1} D\right)$ & $f(\varepsilon)$ & 8.4 & [66] \\
\hline 73 & $\mathrm{e}^{-}+\mathrm{O}_{2} \rightarrow \mathrm{e}^{-}+\mathrm{O}+\mathrm{O}\left({ }^{1} S\right)$ & $f(\varepsilon)$ & 9.97 & [66] \\
\hline 74 & $\mathrm{e}^{-}+\mathrm{O}_{2} \rightarrow 2 \mathrm{e}^{-}+\mathrm{O}_{2}^{+}$ & $f(\varepsilon)$ & 12.1 & [66] \\
\hline 75 & $\mathrm{e}^{-}+\mathrm{O}_{2}^{+} \rightarrow 20$ & $1.2 \times 10^{-14} T_{e}^{-0.7}$ & 0 & [39] \\
\hline 76 & $\mathrm{O}^{-}+\mathrm{O}_{2}+\mathrm{O}_{2} \rightarrow \mathrm{O}_{3}^{-}+\mathrm{O}_{2}$ & $1.1 \times 10^{-42}\left(T_{g} / 300\right)^{-1}$ & 0 & [28] \\
\hline 77 & $\mathrm{O}_{2}^{-}+\mathrm{O} \rightarrow \mathrm{O}^{-}+\mathrm{O}_{2}$ & $1.5 \times 10^{-16}\left(T_{g} / 300\right)^{0.5}$ & 0 & [39] \\
\hline 78 & $\mathrm{O}_{2}^{-}+\mathrm{O}_{3} \rightarrow \mathrm{O}_{3}^{-}+\mathrm{O}_{2}$ & $6 \times 10^{-16}\left(T_{g} / 300\right)^{0.5}$ & 0 & [39] \\
\hline 79 & $\mathrm{O}_{2}(v)+\mathrm{O}_{2} \rightarrow 2 \mathrm{O}_{2}$ & $1 \times 10^{-20}\left(T_{g} / 300\right)^{0.5}$ & 0 & [39] \\
\hline 80 & $\mathrm{O}_{2}^{+}+\mathrm{O}_{3}^{-}+\mathrm{O}_{2} \rightarrow \mathrm{O}_{2}+\mathrm{O}_{3}+\mathrm{O}_{2}$ & $2 \times 10^{-37}\left(T_{g} / 300\right)^{-2.5}$ & 0 & {$[28,52]$} \\
\hline 81 & $\mathrm{O}_{4}^{+}+\mathrm{O}^{-}+\mathrm{O}_{2} \rightarrow 2 \mathrm{O}_{2}+\mathrm{O}+\mathrm{O}_{2}$ & $2 \times 10^{-37}\left(T_{g} / 300\right)^{-2.5}$ & 0 & {$[28,52]$} \\
\hline 82 & $\mathrm{O}_{4}^{+}+\mathrm{O}_{2}^{-}+\mathrm{O}_{2} \rightarrow 3 \mathrm{O}_{2}+\mathrm{O}_{2}$ & $2 \times 10^{-37}\left(T_{g} / 300\right)^{-2.5}$ & 0 & {$[28,52]$} \\
\hline 83 & $\mathrm{O}_{4}^{+}+\mathrm{O}_{3}^{-}+\mathrm{O}_{2} \rightarrow 2 \mathrm{O}_{2}+\mathrm{O}_{3}+\mathrm{O}_{2}$ & $2 \times 10^{-37}\left(T_{g} / 300\right)^{-2.5}$ & 0 & {$[28,52]$} \\
\hline 84 & $\mathrm{O}+\mathrm{O}^{-} \rightarrow \mathrm{e}^{-}+\mathrm{O}_{2}$ & $2 \times 10^{-16}\left(T_{g} / 300\right)^{0.5}$ & 0 & [39] \\
\hline 85 & $\mathrm{O}^{-}+\mathrm{O}_{2}(b) \rightarrow \mathrm{e}^{-}+\mathrm{O}_{2}+\mathrm{O}$ & $6.9 \times 10^{-16}\left(T_{g} / 300\right)^{0.5}$ & 0 & [39] \\
\hline 86 & $\mathrm{O}^{-}+\mathrm{O}_{2}(a) \rightarrow \mathrm{e}^{-}+\mathrm{O}_{3}$ & $3 \times 10^{-16}\left(T_{g} / 300\right)^{0.5}$ & 0 & [39] \\
\hline 87 & $\mathrm{O}_{3}^{-}+\mathrm{O} \rightarrow \mathrm{O}_{2}^{-}+\mathrm{O}_{2}$ & $2.5 \times 10^{-16}\left(T_{g} / 300\right)^{0.5}$ & 0 & [39] \\
\hline
\end{tabular}




\begin{tabular}{|c|c|c|c|c|}
\hline 88 & $\mathrm{O}_{4}^{+}+\mathrm{O} \rightarrow \mathrm{O}_{2}^{+}+\mathrm{O}_{3}$ & $3 \times 10^{-16}$ & 0 & [52] \\
\hline 89 & $\mathrm{O}_{4}^{+}+\mathrm{O}_{2} \rightarrow \mathrm{O}_{2}^{+}+2 \mathrm{O}_{2}$ & $3.3 \times 10^{-12}\left(T_{g} / 300\right)^{-4} e^{\left(-5030 / T_{g}\right)}$ & 0 & [52] \\
\hline 90 & $\mathrm{O}\left({ }^{1} D\right)+\mathrm{O}_{2} \rightarrow \mathrm{O}_{2}+\mathrm{O}$ & $4.8 \times 10^{-18} e^{\left(67 / T_{g}\right)}$ & 0 & {$[91]$} \\
\hline 91 & $\mathrm{O}\left({ }^{1} D\right)+\mathrm{O}_{2} \rightarrow \mathrm{O}_{2}(a)+\mathrm{O}$ & $1.6 \times 10^{-18} e^{\left(67 / T_{g}\right)}$ & 0 & {$[91]$} \\
\hline 92 & $\mathrm{O}\left({ }^{1} D\right)+\mathrm{O}_{2} \rightarrow \mathrm{O}_{2}(b)+\mathrm{O}$ & $2.56 \times 10^{-17} e^{\left(67 / T_{g}\right)}$ & 0 & {$[91]$} \\
\hline 93 & $\mathrm{O}\left({ }^{1} S\right)+\mathrm{O}_{2}(a) \rightarrow \mathrm{O}+\mathrm{O}_{2}$ & $1.1 \times 10^{-16}$ & 0 & [39] \\
\hline 94 & $\mathrm{O}_{2}(b)+\mathrm{O}_{3} \rightarrow 2 \mathrm{O}_{2}+\mathrm{O}$ & $7.33 \times 10^{-18}\left(T_{g} / 300\right)^{0.5}$ & 0 & [39] \\
\hline 95 & $\mathrm{e}^{-}+\mathrm{O}_{4}^{+} \rightarrow 2 \mathrm{O}_{2}$ & $2.25 \times 10^{-13} T_{e}^{-0.5}$ & 0 & [52] \\
\hline 96 & $\mathrm{e}^{-}+\mathrm{O}+\mathrm{He} \rightarrow \mathrm{O}^{-}+\mathrm{He}$ & $1 \times 10^{-43}$ & 0 & {$[28]$} \\
\hline 97 & $\mathrm{e}^{-}+\mathrm{O}_{3}+\mathrm{He} \rightarrow \mathrm{O}_{3}^{-}+\mathrm{He}$ & $1 \times 10^{-43}$ & 0 & [28] \\
\hline 98 & $\mathrm{He}_{2}^{*}+\mathrm{O}_{2} \rightarrow 2 \mathrm{He}+\mathrm{O}_{2}$ & $1.5 \times 10^{-21}$ & 0 & [78] \\
\hline 99 & $\mathrm{O}_{2}(v)+\mathrm{He} \rightarrow \mathrm{O}_{2}+\mathrm{He}$ & $1 \times 10^{-20}\left(T_{g} / 300\right)^{0.5}$ & 0 & [39] \\
\hline 100 & $\mathrm{O}^{-}+\mathrm{O}_{2}+\mathrm{He} \rightarrow \mathrm{O}_{3}^{-}+\mathrm{He}$ & $1.1 \times 10^{-42}\left(T_{g} / 300\right)^{-1}$ & 0 & [28] \\
\hline 101 & $\mathrm{O}_{2}^{+}+\mathrm{O}_{3}^{-}+\mathrm{He} \rightarrow \mathrm{O}_{2}+\mathrm{O}_{3}+\mathrm{He}$ & $2 \times 10^{-37}\left(T_{g} / 300\right)^{-2.5}$ & 0 & {$[28,52]$} \\
\hline 102 & $\mathrm{O}_{4}^{+}+\mathrm{O}^{-}+\mathrm{He} \rightarrow 2 \mathrm{O}_{2}+\mathrm{O}+\mathrm{He}$ & $2 \times 10^{-37}\left(T_{g} / 300\right)^{-2.5}$ & 0 & {$[28,52]$} \\
\hline 103 & $\mathrm{O}_{4}^{+}+\mathrm{O}_{2}^{-}+\mathrm{He} \rightarrow 3 \mathrm{O}_{2}+\mathrm{He}$ & $2 \times 10^{-37}\left(T_{g} / 300\right)^{-2.5}$ & 0 & {$[28,52]$} \\
\hline 104 & $\mathrm{O}_{4}^{+}+\mathrm{O}_{3}^{-}+\mathrm{He} \rightarrow 2 \mathrm{O}_{2}+\mathrm{O}_{3}+\mathrm{He}$ & $2 \times 10^{-37}\left(T_{g} / 300\right)^{-2.5}$ & 0 & {$[28,52]$} \\
\hline 105 & $\mathrm{e}^{-}+\mathrm{O}_{2}+\mathrm{He} \rightarrow \mathrm{He}+\mathrm{O}_{2}^{-}$ & $1 \times 10^{-43}$ & 0 & [43] \\
\hline 106 & $\mathrm{O}_{2}^{+}+\mathrm{O}_{2}+\mathrm{He} \rightarrow \mathrm{O}_{4}^{+}+\mathrm{He}$ & $5.8 \times 10^{-43}\left(T_{g} / 300\right)^{-3.1}$ & 0 & [92] \\
\hline 107 & $\mathrm{He}_{m}+\mathrm{O}_{2} \rightarrow \mathrm{O}_{2}^{+}+\mathrm{He}+\mathrm{e}^{-}$ & $2.54 \times 10^{-16}\left(T_{g} / 300\right)^{0.5}$ & 0 & [39] \\
\hline 108 & $\mathrm{He}_{2}^{*}+\mathrm{O}_{2} \rightarrow \mathrm{O}_{2}^{+}+2 \mathrm{He}+\mathrm{e}^{-}$ & $1 \times 10^{-16}\left(T_{g} / 300\right)^{0.5}$ & 0 & [93] \\
\hline 109 & $\mathrm{O}_{2}+\mathrm{O}+\mathrm{He} \rightarrow \mathrm{O}_{3}+\mathrm{He}$ & $1.1 \times 10^{-46} e^{\left(510 / T_{g}\right)}$ & 0 & [43] \\
\hline 110 & $\mathrm{He}_{2}^{+}+\mathrm{O}_{2} \rightarrow \mathrm{O}_{2}^{+}+2 \mathrm{He}$ & $1 \times 10^{-15}\left(T_{g} / 300\right)^{0.5}$ & 0 & [93] \\
\hline 111 & $\mathrm{O}\left({ }^{1} D\right)+\mathrm{He} \rightarrow \mathrm{O}+\mathrm{He}$ & $1 \times 10^{-19}$ & 0 & [39] \\
\hline 112 & $\mathrm{O}_{2}^{+}+\mathrm{O}^{-}+\mathrm{M} \rightarrow \mathrm{O}_{2}+\mathrm{O}+\mathrm{M}$ & $2 \times 10^{-37}\left(T_{g} / 300\right)^{-2.5}$ & 0 & {$[52,53]$} \\
\hline 113 & $\mathrm{O}_{2}^{+}+\mathrm{O}_{2}^{-}+\mathrm{M} \rightarrow 2 \mathrm{O}_{2}+\mathrm{M}$ & $2 \times 10^{-37}\left(T_{g} / 300\right)^{-2.5}$ & 0 & {$[52,53]$} \\
\hline 114 & $\mathrm{O}_{2}^{+}+\mathrm{O}^{-}+\mathrm{N}_{2} \rightarrow \mathrm{O}_{3}+\mathrm{N}_{2}$ & $2 \times 10^{-37}\left(T_{g} / 300\right)^{-2.5}$ & 0 & {$[52,53]$} \\
\hline 115 & $\mathrm{O}_{2}^{+}+\mathrm{O}_{3}^{-}+\mathrm{N}_{2} \rightarrow \mathrm{O}_{2}+\mathrm{O}_{3}+\mathrm{N}_{2}$ & $1 \times 10^{-37}\left(T_{g} / 300\right)^{-2.5}$ & 0 & {$[52,53]$} \\
\hline 116 & $\mathrm{O}_{4}^{+}+\mathrm{O}^{-}+\mathrm{N}_{2} \rightarrow 2 \mathrm{O}_{2}+\mathrm{O}+\mathrm{N}_{2}$ & $1 \times 10^{-37}\left(T_{g} / 300\right)^{-2.5}$ & 0 & {$[52,53]$} \\
\hline 117 & $\mathrm{O}_{4}^{+}+\mathrm{O}_{2}^{-}+\mathrm{N}_{2} \rightarrow 3 \mathrm{O}_{2}+\mathrm{N}_{2}$ & $1 \times 10^{-37}\left(T_{g} / 300\right)^{-2.5}$ & 0 & {$[52,53]$} \\
\hline 118 & $\mathrm{O}_{4}^{+}+\mathrm{O}_{3}^{-}+\mathrm{N}_{2} \rightarrow 2 \mathrm{O}_{2}+\mathrm{O}_{3}+\mathrm{N}_{2}$ & $1 \times 10^{-37}\left(T_{g} / 300\right)^{-2.5}$ & 0 & {$[52,53]$} \\
\hline 119 & $\mathrm{~N}_{2}^{+}+\mathrm{O}^{-}+\mathrm{O}_{2} \rightarrow \mathrm{N}_{2}+\mathrm{O}+\mathrm{O}_{2}$ & $2 \times 10^{-37}\left(T_{g} / 300\right)^{-2.5}$ & 0 & {$[52,53]$} \\
\hline 120 & $\mathrm{~N}_{2}^{+}+\mathrm{O}^{-}+\mathrm{N}_{2} \rightarrow \mathrm{N}_{2}+\mathrm{O}+\mathrm{N}_{2}$ & $2 \times 10^{-37}\left(T_{g} / 300\right)^{-2.5}$ & 0 & {$[52,53]$} \\
\hline 121 & $\mathrm{~N}_{2}^{+}+\mathrm{O}_{2}^{-}+\mathrm{O}_{2} \rightarrow \mathrm{N}_{2}+\mathrm{O}_{2}+\mathrm{O}_{2}$ & $2 \times 10^{-37}\left(T_{g} / 300\right)^{-2.5}$ & 0 & {$[52,53]$} \\
\hline 122 & $\mathrm{~N}_{2}^{+}+\mathrm{O}_{2}^{-}+\mathrm{N}_{2} \rightarrow \mathrm{N}_{2}+\mathrm{O}_{2}+\mathrm{N}_{2}$ & $2 \times 10^{-37}\left(T_{g} / 300\right)^{-2.5}$ & 0 & {$[52,53]$} \\
\hline 123 & $\mathrm{~N}_{2}^{+}+\mathrm{O}_{2}+\mathrm{e}^{-} \rightarrow \mathrm{O}_{2}+\mathrm{N}_{2}$ & $6 \times 10^{-39}\left(T_{e} / T_{g}\right)^{-1.5}$ & 0 & [53] \\
\hline 124 & $\mathrm{O}_{2}^{+}+\mathrm{N}_{2}+\mathrm{e}^{-} \rightarrow \mathrm{O}_{2}+\mathrm{N}_{2}$ & $6 \times 10^{-39}\left(T_{e} / T_{g}\right)^{-1.5}$ & 0 & [53] \\
\hline 125 & $\mathrm{O}_{2}+\mathrm{N}+\mathrm{N} \rightarrow \mathrm{O}_{2}+\mathrm{N}_{2}$ & $3.9 \times 10^{-45}$ & 0 & [53] \\
\hline 126 & $\mathrm{O}+\mathrm{O}_{2}+\mathrm{N}_{2} \rightarrow \mathrm{O}_{3}+\mathrm{N}_{2}$ & $1.1 \times 10^{-46} \exp \left(510 / T_{g}\right)$ & 0 & [53] \\
\hline 127 & $\mathrm{O}+\mathrm{O}+\mathrm{N}_{2} \rightarrow \mathrm{O}_{2}+\mathrm{N}_{2}$ & $6.49 \times 10^{-47} \exp \left(1039 / T_{g}\right)$ & 0 & [53] \\
\hline 128 & $\mathrm{O}+\mathrm{O}+\mathrm{N} \rightarrow \mathrm{O}_{2}+\mathrm{N}$ & $3.2 \times 10^{-45}\left(T_{g} / 300\right)^{-0.41}$ & 0 & [53] \\
\hline 129 & $\mathrm{O}_{3}+\mathrm{N}_{2} \rightarrow \mathrm{O}+\mathrm{O}_{2}+\mathrm{N}_{2}$ & $1.6 \times 10^{-15} \exp \left(-11400 / T_{g}\right)$ & 0 & [53] \\
\hline 130 & $\mathrm{O}\left({ }^{1} S\right)+\mathrm{N}_{2} \rightarrow \mathrm{O}+\mathrm{N}_{2}$ & $1.6 \times 10^{-23}$ & 0 & [53] \\
\hline 131 & $\mathrm{O}\left({ }^{1} D\right)+\mathrm{N}_{2} \rightarrow \mathrm{O}+\mathrm{N}_{2}$ & $1.8 \times 10^{-17} \exp \left(107 / T_{g}\right)$ & 0 & [53] \\
\hline
\end{tabular}




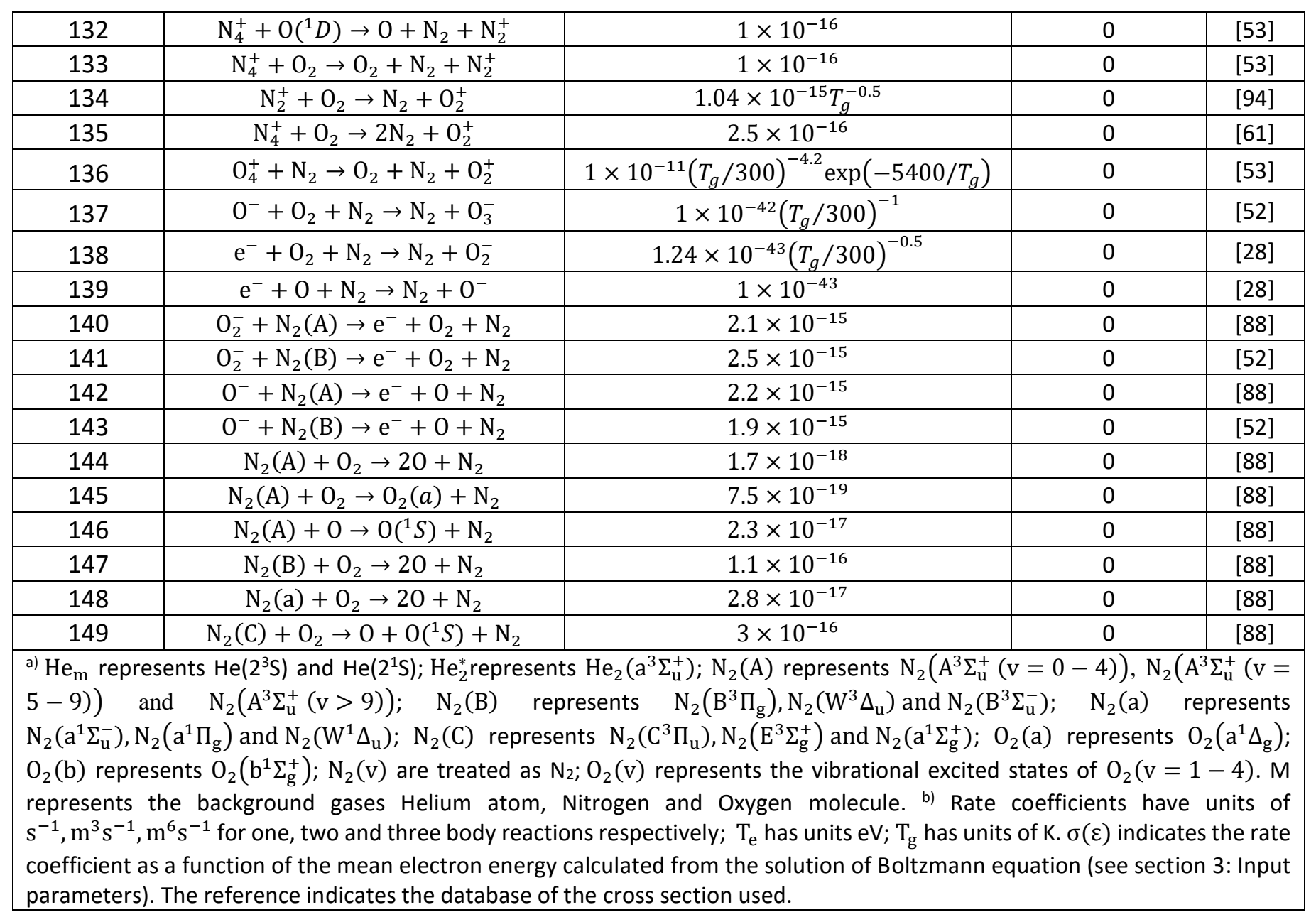

References:

[1] Belmonte T, Pintassilgo C D, Czerwiec T, Henrion G, Hody V, Thiebaut J M and Loureiro J 2005 Oxygen plasma surface interaction in treatments of polyolefines Surf. Coatings Technol. 200 26-30

[2] Deng X T, Shi J J and Kong M G 2007 Protein destruction by a helium atmospheric pressure glow discharge: Capability and mechanisms J. Appl. Phys. 101074701

[3] Bhoj A N and Kushner M J 2008 Repetitively pulsed atmospheric pressure discharge treatment of rough polymer surfaces: I. Humid air discharges Plasma Sources Sci. Technol. 17035024

[4] Iza F, Kim G J, Lee S M, Lee J K, Walsh J L, Zhang Y T and Kong M G 2008 Microplasmas: Sources, Particle Kinetics, and Biomedical Applications Plasma Process. Polym. 5 322-44

[5] Kong M G, Kroesen G, Morfill G, Nosenko T, Shimizu T, van Dijk J and Zimmermann J L 2009 Plasma medicine: an introductory review New J. Phys. 11 115012

[6] Nastuta A V, Topala I, Grigoras C, Pohoata V and Popa G 2011 Stimulation of wound healing by helium atmospheric pressure plasma treatment J. Phys. D. Appl. Phys. 44105204

[7] Kelly-Wintenberg K, Montie T C, Brickman C, Roth J R, Carr A K, Sorge K, Wadsworth L C and Tsai P P Y 1998 Room temperature sterilization of surfaces and fabrics with a One Atmosphere Uniform Glow Discharge Plasma J. Ind. Microbiol. Biotechnol. 20 69-74

[8] Laroussi M 2005 Low Temperature Plasma-Based Sterilization: Overview and Stateof-the-Art Plasma Process. Polym. 2 391-400

[9] Mfopara A, Kirkpatrick M J and Odic E 2008 Dilute Methane Treatment by 
Atmospheric Pressure Dielectric Barrier Discharge: Effects of Water Vapor Plasma Chem. Plasma Process. 29 91-102

[10] Kogelschatz U 2003 Dielectric-barrier Discharges : Their History, Discharge Physics , and Industrial Applications 23 1-46

[11] Massines F, Gherardi N, Naudé N and Ségur P 2009 Recent advances in the understanding of homogeneous dielectric barrier discharges Eur. Phys. J. Appl. Phys. 4722805

[12] Massines F, Rabehi A, Decomps P, Gadri R Ben, Ségur P and Mayoux C 1998 Experimental and theoretical study of a glow discharge at atmospheric pressure controlled by dielectric barrier J. Appl. Phys. 832950

[13] Mangolini L, Anderson C, Heberlein J and Kortshagen U 2004 Effects of current limitation through the dielectric in atmospheric pressure glows in helium J. Phys. D. Appl. Phys. 37 1021-30

[14] Nersisyan G and Graham W G 2004 Characterization of a dielectric barrier discharge operating in an open reactor with flowing helium Plasma Sources Sci. Technol. 13 $582-7$

[15] Navrátil Z, Brandenburg R, Trunec D, Brablec A, St'ahel P, Wagner H-E and Kopecký Z 2006 Comparative study of diffuse barrier discharges in neon and helium Plasma Sources Sci. Technol. 15 8-17

[16] Trunec D, Brablec A and Buchta J 2001 Atmospheric pressure glow discharge in neon J. Phys. D. Appl. Phys. 34 1697-9

[17] Ran J, Luo H and Wang X 2011 A dielectric barrier discharge in neon at atmospheric pressure J. Phys. D. Appl. Phys. 44335203

[18] Chiper A S, Cazan R and Popa G 2008 On the Secondary Discharge of an Atmospheric-Pressure Pulsed DBD in He with Impurities IEEE Trans. Plasma Sci. 36 2824-30

[19] Sublet A, Ding C, Dorier J-L, Hollenstein C, Fayet P and Coursimault F 2006 Atmospheric and sub-atmospheric dielectric barrier discharges in helium and nitrogen Plasma Sources Sci. Technol. 15 627-34

[20] Massines F, Gherardi N, Naudé N and Ségur P 2005 Glow and Townsend dielectric barrier discharge in various atmosphere Plasma Phys. Control. Fusion 47 B577-88

[21] De Geyter N, Morent R, Desmet T, Trentesaux M, Gengembre L, Dubruel P, Leys C and Payen E 2010 Plasma modification of polylactic acid in a medium pressure DBD Surf. Coatings Technol. 204 3272-9

[22] Brandenburg R, Navrátil Z, Jánský J, St'ahel P, Trunec D and Wagner H-E 2009 The transition between different modes of barrier discharges at atmospheric pressure $J$. Phys. D. Appl. Phys. 42085208

[23] Bogaczyk M, Sretenović G B and Wagner H-E 2013 Influence of the applied voltage shape on the barrier discharge operation modes in helium Eur. Phys. J. D 67212

[24] Dosoudilová L, Tschiersch R, Bogaczyk M, Navrátil Z, Wagner H-E and Trunec D 2015 Investigation of helium barrier discharges with small admixtures of oxygen $J$. Phys. D. Appl. Phys. 48355204

[25] Kanazawa S, Kogoma M, Moriwaki T and Okazaki S 1988 Stable glow plasma at atmospheric pressure J. Phys. D. Appl. Phys. 21 838-40

[26] Okazaki S, Kogoma M, Uehara M and Kimura Y 1993 Appearance of stable glow discharge in air, argon, oxygen and nitrogen at atmospheric pressure using a $50 \mathrm{~Hz}$ source J. Phys. D. Appl. Phys. 26 889-92

[27] Lazarou C, Koukounis D, Chiper A S, Costin C, Topala I and Georghiou G E 2015 Numerical modeling of the effect of the level of nitrogen impurities in a helium parallel plate dielectric barrier discharge Plasma Sources Sci. Technol. 24035012

[28] Liu D-X, Rong M-Z, Wang X-H, Iza F, Kong M G and Bruggeman P 2010 Main Species and Physicochemical Processes in Cold Atmospheric-pressure $\mathrm{He}+\mathrm{O} 2$ Plasmas Plasma Process. Polym. 7 846-65

[29] Park G Y, Hong Y J, Lee H W, Sim J Y and Lee J K 2010 A Global Model for the Identification of the Dominant Reactions for Atomic Oxygen in He/O 2 Atmospheric- 
Pressure Plasmas Plasma Process. Polym. 7 281-7

[30] Martens T, Bogaerts A, Brok W J M and Dijk J V. 2008 The dominant role of impurities in the composition of high pressure noble gas plasmas Appl. Phys. Lett. 92 041504

[31] Martens T, Bogaerts A, Brok W J M and van Dijk J 2010 The influence of impurities on the performance of the dielectric barrier discharge Appl. Phys. Lett. 96091501

[32] Bourdon A, Darny T, Pechereau F, Pouvesle J-M, Viegas P, Iséni S and Robert E 2016 Numerical and experimental study of the dynamics of a $\mu \mathrm{s}$ helium plasma gun discharge with various amounts of N 2 admixture Plasma Sources Sci. Technol. 25 035002

[33] Tschiersch R, Bogaczyk M and Wagner H-E 2014 Systematic investigation of the barrier discharge operation in helium, nitrogen, and mixtures: discharge development, formation and decay of surface charges J. Phys. D. Appl. Phys. 47365204

[34] Chiper A S, Aniţa V, Agheorghiesei C, Pohoaţa V, Aniţa M and Popa G 2004 Spectroscopic Diagnostics for a DBD Plasma in He/Air and He/N2 Gas Mixtures Plasma Process. Polym. 1 57-62

[35] Jansky J, Algwari Q T, O'Connell D and Bourdon A 2012 Experimental-Modeling Study of an Atmospheric-Pressure Helium Discharge Propagating in a Thin Dielectric Tube IEEE Trans. Plasma Sci. $402912-9$

[36] Lazzaroni C, Chabert P, Lieberman M A, Lichtenberg A J and Leblanc A 2012 Analytical-numerical global model of atmospheric-pressure radio-frequency capacitive discharges Plasma Sources Sci. Technol. 21035013

[37] Jánský J and Bourdon A 2014 Simulation of two counter-propagating helium discharges at atmospheric pressure Plasma Sources Sci. Technol. 23025001

[38] Lieberman M A 2015 Analytical model of atmospheric pressure, helium/trace gas radio-frequency capacitive Penning discharges Plasma Sources Sci. Technol. 24 025009

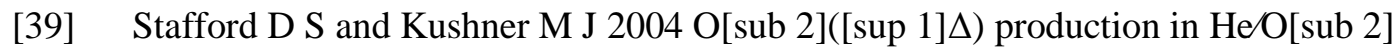
mixtures in flowing low pressure plasmas J. Appl. Phys. 962451

[40] Turner M M 2016 Uncertainty and sensitivity analysis in complex plasma chemistry models Plasma Sources Sci. Technol. 25015003

[41] Naidis G V. 2012 Modeling of helium plasma jets emerged into ambient air: Influence of applied voltage, jet radius, and helium flow velocity on plasma jet characteristics J. Appl. Phys. 112103304

[42] Naidis G V 2010 Modelling of streamer propagation in atmospheric-pressure helium plasma jets J. Phys. D. Appl. Phys. 43402001

[43] Stalder K R, Vidmar R J, Nersisyan G and Graham W G 2006 Modeling the chemical kinetics of high-pressure glow discharges in mixtures of helium with real air J. Appl. Phys. 99093301

[44] Iqbal M M and Turner M M 2015 Influence of Gap Spacing between Dielectric Barriers in Atmospheric Pressure Discharges Contrib. to Plasma Phys. 55 444-58

[45] Lin K-M, Hung C-T, Hwang F-N, Smith M R, Yang Y-W and Wu J-S 2012 Development of a parallel semi-implicit two-dimensional plasma fluid modeling code using finite-volume method Comput. Phys. Commun. 183 1225-36

[46] Hagelaar G J M, Kroesen G M W, van Slooten U and Schreuders H 2000 Modeling of the microdischarges in plasma addressed liquid crystal displays J. Appl. Phys. $\mathbf{8 8} 2252$

[47] Gogolides E and Sawin H H 1992 Continuum modeling of radio-frequency glow discharges. I. Theory and results for electropositive and electronegative gases J. Appl. Phys. 723971

[48] Hagelaar G J M and Pitchford L C 2005 Solving the Boltzmann equation to obtain electron transport coefficients and rate coefficients for fluid models Plasma Sources Sci. Technol. 14 722-33

[49] Bird R B, Stewart W E and Lightfoot E N 2002 Transport phenomena vol 15 (Wiley)

[50] Kee R J, Coltrin M E and Glarborg P 2003 Chemically Reacting Flow Theory and Practice (Wiley) 
[51] http://www.comsol.com/plasma-module

[52] Kossyi I A, Kostinsky A Y, Matveyev A A and Silakov V P 1992 Kinetic scheme of the non-equilibrium discharge in nitrogen-oxygen mixtures Plasma Sources Sci. Technol. 1 207-20

[53] Murakami T, Niemi K, Gans T, O’Connell D and Graham W G 2013 Chemical kinetics and reactive species in atmospheric pressure helium-oxygen plasmas with humid-air impurities Plasma Sources Sci. Technol. 22015003

[54] Belmonte T, Cardoso R P, Henrion G and Kosior F 2007 Collisional-radiative modelling of a helium microwave plasma in a resonant cavity J. Phys. D. Appl. Phys. $407343-56$

[55] Pouvesle J M 1982 Modeling of the charge transfer afterglow excited by intense electrical discharges in high pressure helium nitrogen mixtures J. Chem. Phys. 77817

[56] Alves L L 2007 Fluid modelling of the positive column of direct-current glow discharges Plasma Sources Sci. Technol. 16 557-69

[57] www.lxcat.laplace.univ-tlse.fr/

[58] Longo S and Capitelli M 1994 A simple approach to treat anisotropic elastic collisions in Monte Carlo calculations of the electron energy distribution function in cold plasmas Plasma Chem. Plasma Process. 14 1-13

[59] Biagi S F 1999 Monte Carlo simulation of electron drift and diffusion in counting gases under the influence of electric and magnetic fields Nucl. Instruments Methods Phys. Res. Sect. A Accel. Spectrometers, Detect. Assoc. Equip. $421234-40$

[60] Alves L L, Bartschat K, Biagi S F, Bordage M C, Pitchford L C, Ferreira C M, Hagelaar G J M, Morgan W L, Pancheshnyi S, Phelps A V, Puech V and Zatsarinny O 2013 Comparisons of sets of electron-neutral scattering cross sections and swarm parameters in noble gases: II. Helium and neon J. Phys. D. Appl. Phys. 46334002

[61] Brandenburg R, Maiorov V A, Golubovskii Y B, Wagner H-E, Behnke J and Behnke J F 2005 Diffuse barrier discharges in nitrogen with small admixtures of oxygen: discharge mechanism and transition to the filamentary regime J. Phys. D. Appl. Phys. 38 2187-97

[62] Pancheshnyi S, Biagi S, Bordage M C, Hagelaar G J M, Morgan W L, Phelps A V and Pitchford L C 2012 The LXCat project: Electron scattering cross sections and swarm parameters for low temperature plasma modeling Chem. Phys. 398 148-53

[63] Pitchford L C, Alves L L, Bartschat K, Biagi S F, Bordage M C, Phelps A V, Ferreira C M, Hagelaar G J M, Morgan W L, Pancheshnyi S, Puech V, Stauffer A and Zatsarinny O 2013 Comparisons of sets of electron-neutral scattering cross sections and swarm parameters in noble gases: I. Argon J. Phys. D. Appl. Phys. 46334001

[64] Bordage M C, Biagi S F, Alves L L, Bartschat K, Chowdhury S, Pitchford L C, Hagelaar G J M, Morgan W L, Puech V and Zatsarinny O 2013 Comparisons of sets of electron-neutral scattering cross sections and swarm parameters in noble gases: III. Krypton and xenon J. Phys. D. Appl. Phys. 46334003

[65] Morgan database, www.lxcat.net, retrieved on September 25, 2015

[66] IST-Lisbon database, www.lxcat.net, retrieved on September 25, 2015

[67] Alves L L 2014 The IST-LISBON database on LXCat J. Phys. Conf. Ser. 565012007

[68] TRINITI database, www.lxcat.net, retrieved on September 25, 2015

[69] Neufeld P D 1972 Empirical Equations to Calculate 16 of the Transport Collision Integrals $\Omega(1, \mathrm{~s}) J$. Chem. Phys. 571100

[70] Brokaw R S 1969 Predicting Transport Properties of Dilute Gases Ind. Eng. Chem. Process Des. Dev. 8 240-53

[71] Raja L L 2003 Computational study of capacitively coupled high-pressure glow discharges in helium IEEE Trans. Plasma Sci. 31 495-503

[72] Ellis H W, Pai R Y, McDaniel E W, Mason E A and Viehland L A 1976 Transport properties of gaseous ions over a wide energy range At. Data Nucl. Data Tables 17 $177-210$

[73] Viehland database, www.lxcat.net, retrieved on Feb 23, 2014.

[74] Liu D X, Bruggeman P, Iza F, Rong M Z and Kong M G 2010 Global model of low- 
temperature atmospheric-pressure He + H 2 O plasmas Plasma Sources Sci. Technol. 19025018

[75] Babaeva N Y and Kushner M J 2013 Reactive fluxes delivered by dielectric barrier discharge filaments to slightly wounded skin J. Phys. D. Appl. Phys. 46025401

[76] Bogaczyk M, Wild R, Stollenwerk L and Wagner H-E 2012 Surface charge accumulation and discharge development in diffuse and filamentary barrier discharges operating in He, N 2 and mixtures J. Phys. D. Appl. Phys. 45465202

[77] Zhang P and Kortshagen U 2006 Two-dimensional numerical study of atmospheric pressure glows in helium with impurities J. Phys. D. Appl. Phys. 39 153-63

[78] Golubovskii Y B, Maiorov V A, Behnke J and Behnke J F 2003 Modelling of the homogeneous barrier discharge in helium at atmospheric pressure J. Phys. D. Appl. Phys. 36 39-49

[79] Janev R K, Langer W D, Post D E and Evans K 1987 Elementary Processes in Hydrogen-Helium Plasmas (Berlin, Heidelberg: Springer Berlin Heidelberg)

[80] Deloche R, Monchicourt P, Cheret M and Lambert F 1976 High-pressure helium afterglow at room temperature $\mathbf{1 3}$

[81] Stevefelt J 1982 Reaction kinetics of a high pressure helium fast discharge afterglow J. Chem. Phys. 764006

[82] Konstantinovskii R S, Shibkov V M and Shibkova L V 2005 Effect of a Gas Discharge on the Ignition in the Hydrogen - Oxygen System 46 821-34

[83] Wang Q, Economou D J and Donnelly V M 2006 Simulation of a direct current microplasma discharge in helium at atmospheric pressure J. Appl. Phys. 100023301

[84] Millar T J, Farquhar P R A and Willacy K 1997 The UMIST database for astrochemistry 1995185 139-85

[85] Gordillo-Vázquez F J 2008 Air plasma kinetics under the influence of sprites J. Phys. D. Appl. Phys. 41234016

[86] Castillo M, Méndez I, Islyaikin A M, Herrero V J and Tanarro I 2005 Low-pressure DC air plasmas. investigation of neutral and ion chemistry. J. Phys. Chem. A 109 6255-63

[87] Sommerer T J and Kushner M J 1992 Numerical investigation of the kinetics and chemistry of rf glow discharge plasmas sustained in $\mathrm{He}, \mathrm{N} 2, \mathrm{O} 2, \mathrm{He} / \mathrm{N} 2 / \mathrm{O} 2$, $\mathrm{He} / \mathrm{CF} 4 / \mathrm{O} 2$, and $\mathrm{SiH} 4 / \mathrm{NH} 3$ using a Monte Carlo-fluid hybrid model J. Appl. Phys. 71 1654

[88] Tochikubo F, Uchida S, Yasui H and Sato K 2009 Numerical Simulation of NO Oxidation in Dielectric Barrier Discharge with Microdischarge Formation Jpn. J. Appl. Phys. 48076507

[89] Capitelli M, Ferreira C M, Gordiets B F and Osipov A I 2000 Plasma Kinetics in Atmospheric Gases vol 31 (Berlin, Heidelberg: Springer Berlin Heidelberg)

[90] Margot J, Petrov G M, Matte J P, Pe I, Sadi T, Hubert J, Tran K C, Alves L L, Loureiro J, Ferreira C M and Guerra V 2000 Numerical Modeling of a He - N 2 Capillary Surface' re $\mathbf{2 0}$

[91] Atkinson R, Baulch D L, Cox R A, Hampson R F, Kerr J A, Rossi M J and Troe J 1997 Evaluated Kinetic, Photochemical and Heterogeneous Data for Atmospheric Chemistry: Supplement V. IUPAC Subcommittee on Gas Kinetic Data Evaluation for Atmospheric Chemistry J. Phys. Chem. Ref. Data 26521

[92] Good A 1975 Third-order ion-molecule clustering reactions Chem. Rev. 75 561-83

[93] Cardoso R P, Belmonte T, Henrion G and Sadeghi N 2006 Influence of trace oxygen on $\mathrm{He}(23 \mathrm{~S})$ density in a $\mathrm{He}-\mathrm{O} 2$ microwave discharge at atmospheric pressure: behaviour of the time afterglow J. Phys. D. Appl. Phys. 39 4178-85

[94] Kelly S and Turner M M 2013 Atomic oxygen patterning from a biomedical needleplasma source J. Appl. Phys. 114123301 